\title{
Synthesis of nanocapsules and polymer/inorganic nanoparticles through controlled radical polymerization at and near interfaces in heterogeneous media
}

\author{
Elodie Bourgeat-Lami, Franck D'Agosto, Muriel Lansalot* \\ 1 Université de Lyon, Univ. Lyon 1, CPE Lyon, CNRS UMR 5265, Laboratoire de Chimie, \\ Catalyse, Polymères et Procédés (C2P2), LCPP group, 69616 Villeurbanne, France. \\ * muriel.lansalot@univ-lyon1.fr
}

\begin{abstract}
This review article describes recent advances in the synthesis of polymeric nanocapsules and polymer/inorganic hybrid nanoparticles where controlled radical polymerization (CRP) has been used in (mini)emulsion systems to restrict the polymerization to an interface. For the synthesis of nanocapsules, CRP polymers stabilize the initial miniemulsion droplet interface and are chain extended mainly towards the center of the droplets comprising of an inert liquid core. In the encapsulation of inorganic particles, CRP polymers adsorbed on their surface are chain extended to form a polymer shell around the inorganic core. Precise control over the polymers' structures and compositions allows their location to be restricted to these interfaces. Polymerization in the subsequent (mini)emulsion system then commences from these specific locations courtesy of the reactivatable functions. The developed strategies retain the advantages of traditional emulsion or miniemulsion systems, while greatly expanding their potential to generate novel nanostructured functional materials.
\end{abstract}

Keywords: controlled radical polymerization, RAFT, NMP, ATRP, emulsion polymerization, miniemulsion polymerization, inorganic particles, capsules, composite materials, encapsulation.

\section{INTRODUCTION}

Free-radical polymerization is arguably the most important method for the production of synthetic polymers in view of its widespread industrial use and the large variety of applications for resulting polymers. A wide range of functional monomers can be (co)polymerized by free-radical polymerization to produce a myriad of polymer compositions and properties [1], but the unavoidable occurrence of fast radical-radical termination reactions means that their molar masses, chain-end functionalities and macromolecular architectures cannot be controlled. In the last two decades, the development of controlled radical polymerization (CRP) techniques (IUPAC: reversibledeactivation radical polymerization, RDRP) has tremendously impacted the polymer field by overcoming these limitations. CRP techniques can be subdivided into two categories: those based on a reversible termination reaction and those based on a 
reversible chain transfer reaction. In both cases, macromolecular radicals, called active species, undergo reversible deactivation with a controlling agent to form dormant chains (with the controlling functionalities at their termini). Only a very small fraction of chains are simultaneously active and therefore capable of propagation, but rapid interchange of the active centers between macromolecular chains means that all chains have an equal chance to propagate. CRP systems therefore display narrow molar mass distributions and a linear increase in the number-average molar mass $\left(M_{\mathrm{n}}\right)$ with monomer conversion, since the polymer chains grow concurrently. The production of block copolymers and more complex architectures is also possible, since polymers produced by CRP bear the mediating function at the chain end and can thus be further extended with either the same or another monomer in a subsequent polymerization step.

Emulsion polymerization is an important industrial process for the production of latex paints, rubbers, coatings and adhesives [2-4]. A "conventional" emulsion polymerization starts with the emulsification of an insoluble (or scarcely soluble) monomer in water with the aid of a surfactant. A hydrophilic initiator is also present in the water phase. At this point, the monomer is primarily distributed between large emulsion droplets and small surfactant micelles, with a minor amount also dissolved in the aqueous phase. Polymerization starts in the aqueous phase by the formation of free radicals from the initiator and the addition of the first monomer units. These oligomeric radical species are rapidly captured by the monomer-swollen micelles leading to particle formation in the nucleation step, where their continued propagation is supported by the supply of monomer molecules diffusing through the aqueous phase from the large droplets. In surfactant-free emulsion polymerizations, the nucleation occurs by the precipitation of the oligoradicals to form unstable nuclei, which fuse to form larger particles. Polymerization takes place mainly within these monomer-swollen particles, which grow in a similar fashion to the surfactant-containing system.

In the last twenty years, emulsion polymerization has proven highly suitable for the production of polymer/inorganic particles to generate a variety of composite colloids. These can be further processed into films with improved mechanical, thermal or barrier properties compared with their pure-polymer counterparts [5-7]. The encapsulation of inorganic nano-objects into polymer particles can be achieved by either physical adsorption of pre-formed polymer chains or particles onto the inorganic particles, or encapsulation of inorganics within the polymer latex by using them as seeds in the emulsion polymerization process. To circumvent the lack of compatibility between the inorganic and organic parts, coupling agents like silanes, titanates or carboxylates and surfactants are usually employed to render the inorganic surface more hydrophobic.

Miniemulsion polymerization is another widely employed tool to produce polymer/inorganic nanoparticles in dispersed systems [8-12]. In miniemulsion polymerization, high shear is initially applied to the suspension of monomer in a dispersing phase to produce small uniform monomer droplets. Stability is maintained by the presence of a surfactant and also by the use of a solvophobic species that suppresses 
molecular diffusion between droplets. These droplets then accept radicals produced in the initiation step and polymerize to form the final latex particles. In an ideal miniemulsion polymerization, every droplet is nucleated to produce a one to one particle copy. When performed in water, miniemulsion polymerization combines the features of an emulsion polymerization with the possibility to disperse a hydrophobic species inside the monomer droplets. By avoiding the often complicated nucleation step observed in emulsion polymerization, the miniemulsion process is a powerful tool to encapsulate compatible components, including inert liquids and inorganic particles, into the latexes [13-18].

Regardless of the synthetic strategy, controlling the size and the morphology of latex particles is key to modulating the properties of the final material. The use of CRP in emulsion and miniemulsion systems can enhance the possibilities to fine-tune the particle composition and morphology by controlling the polymer chains at the molecular level, thus opening the door to well-defined materials for a variety of new applications. The achievements of CRP in dispersed media have been covered in several excellent review articles [19-22]. The present work will focus more specifically on recent advances in the use of well-defined CRP polymers to generate nanocapsules and polymer-inorganic hybrid nanostructures in heterogeneous systems. Particular attention will be placed on the use of CRP polymers as reactivatable precursors in the (mini)emulsion systems. Since CRP allows tuning of these polymers' physico-chemical properties to precisely direct their location at the respective interface, reactivation of their dormant end-groups permits to resume the polymerization at these specific loci.

\section{GENERAL OVERVIEW OF CONTROLLED RADICAL POLYMERIZATION (CRP) TECHNIQUES}

CRP techniques are classed as either reversible termination processes or reversible chain transfer processes. Within the first category, nitroxide-mediated polymerization (NMP) [23] and atom transfer radical polymerization (ATRP) [24] represent the two most commonly used methods. In NMP, control is induced by nitroxide derivatives, which are capable of reversibly capping active radicals to form dormant alkoxyamines. While alkoxyamines are stable at low temperatures, their $\mathrm{C}-\mathrm{O}$ bonds may undergo reversible homolytic cleavage at elevated temperatures, regenerating active radicals which can add a few monomer units before being once more capped by the nitroxide. This equilibrium between propagating radicals and dormant macroalkoxyamines governs NMP. In ATRP, an alkyl halide initiator is activated by a redox reaction with a transition metal complex. In this reaction, the alkyl halide is reduced to produce an active radical capable of propagation, while the transition metal is oxidized. In most ATRP systems, $\mathrm{Cu}(\mathrm{I})$ species complexed by multidentate amine ligands are used as activators. After the activation step, the propagating radical can add monomer for a short time before being deactivated again through the reverse process: oxidation of the propagating radical by the $\mathrm{Cu}$ (II) complex to regenerate an alkyl halide 
and the original $\mathrm{Cu}(\mathrm{I})$ activator. The activation step can be performed using different approaches starting either from $\mathrm{Cu}(\mathrm{I})$ or from $\mathrm{Cu}(\mathrm{II})$. If $\mathrm{Cu}(\mathrm{I})$ is used, the process is called direct ATRP, and only the alkyl halide is employed as initiator. If $\mathrm{Cu}(\mathrm{II})$ is used, there are multiple initiation possibilities, including the reverse ATRP process [24] which uses a classical radical initiator, the simultaneous reverse and normal initiation (SR\&NI) method [25] which utilizes an alkyl halide in conjunction with a small fraction of a classical radical initiator to reduce $\mathrm{Cu}(\mathrm{II})$ to $\mathrm{Cu}(\mathrm{I})$, the activator (re)generated by electron transfer (A(R)GET) technique [26] which uses an alkyl halide initiator in combination with a reducing agent to turn $\mathrm{Cu}(\mathrm{II})$ into $\mathrm{Cu}(\mathrm{I})$, and e-ATRP [27] which utilizes the concept of ARGET-ATRP via an electrochemical stimulus to provide enhanced polymerization control.

CRP methods proceeding according to a reversible transfer mechanism (also called degenerative transfer (DT) processes) rely on a conventional radical initiator to generate a small number of active radicals, with the presence of a reversible chain transfer agent in large excess allowing the active radicals to be continuously redistributed between a large number of chains. Chains which are not active contain this chain transfer agent as their end group. In (reverse) iodine-transfer polymerization, (R)ITP, an iodine atom is transferred between active chains [28-30]. Organotelluriummediated living radical polymerization (TERP) follows a similar mechanism [31], with the exchange of a terminal $-\mathrm{TeCH}_{3}$ group. The most popular DT technique is reversible addition-fragmentation chain transfer (RAFT) polymerization [32,33] which utilizes a thiocarbonyl (i.e. $\mathrm{C}=\mathrm{S}$ based) compound-typically a dithioester, dithiocarbonate, dithiocarbamate or trithiocarbonate-as chain transfer agent (denoted Z-C $(=\mathrm{S})-\mathrm{SR})$. A radical can add to the thiocarbonyl group to generate a tertiary carbon-based radical intermediate, which then fragments to release a second radical (the "R group" of the RAFT agent) also capable of propagating. In this manner, the active radical functions are rapidly and continually transferred between all the growing chains. If the initial concentration of the radical initiator is low with respect to the initial concentration of the transfer agent, a large majority of the macromolecules have the same RAFT agentderived end-groups and the concentration of growing macromolecular chains becomes constant and close to the initial concentration of the RAFT agent. Precise molar masses can therefore be targeted by simply adjusting the feed ratio of monomer to RAFT agent.

\section{SYNTHESIS OF POLYMERIC NANOCAPSULES}

Nanocapsules are latex particles with a hollow or non-polymeric core, and heterogeneous polymerization systems employing CRP polymers at an interface have proven particularly amenable to their synthesis. The first method for nanocapsule synthesis in dispersed media using controlled radical polymerization is to mix a compatible inert liquid (also called a templating liquid) with the monomer in a miniemulsion system stabilized by CRP polymers. The inert liquid is subsequently entrapped in the core of the latex particles after polymerization. Post-polymerization 
removal of this liquid generates hollow particles which are interesting for a variety of applications including drug delivery $[17,11]$. CRP (typically RAFT and ATRP) is central to this approach since carefully designed controlling agents allow the polymerization to be confined to the interface of the dispersed and continuous phases and thereby entrap the templating liquid in the particle cores [34]. Most studies describing this approach employ oil-in-water miniemulsion (also called direct miniemulsion) systems, as detailed in Section 3.1. Inverse miniemulsion systems, in which hydrophilic monomer droplets swollen with water are polymerized in an organic dispersing phase, have also been successfully reported and are the main systems detailed in Section 3.2. An alternative approach to generate nanocapsules by using vesicles rather than liquids as templates constitutes Section 3.3. Here, CRP polymers are electrostatically adsorbed on the surface of the vesicles, and a hydrophobic polymer shell is grown from this locus via emulsion polymerization.

\subsection{Direct miniemulsion}

\subsubsection{Non-crosslinked nanocapsules}

The first example on the use of CRP in miniemulsion to produce nanocapsules was reported by van Zyl et al. [35] who employed a RAFT agent for the ab initio miniemulsion polymerization of styrene (S). It is important to note that in this example, the dispersed phase was stabilized by a traditional surfactant (rather than a CRP polymer), with the CRP polymer generated in situ in the continuous phase before joining the surfactant at the interface. More specifically, the starting miniemulsion was formed in presence of sodium dodecyl sulfate (SDS) as surfactant with iso-octane used as the templating liquid in the $S$ droplets. Fine-tuning of the polymerization kinetics and surface effects allowed the droplet-entering oligomeric species to be anchored at the surface of the particles where the polymerization continued. Systems employing phenyl 2-propyl dithiobenzoate and phenyl 2-propyl phenyldithioacetate (PPPDTA) as molecular chain transfer agents and potassium persulfate (KPS) or 2,2'azobis(isobutyronitrile) (AIBN) as initiators were trialed. The use of AIBN did not lead to surface-active oligomeric species and thus favored confinement of the formed chains inside the particles. However, PPPDTA used in conjunction with KPS generated surfaceactive oligomeric species which resided at the water/monomer droplet interface. A rapid increase of the molar mass of the chains was observed, leading to a reduced mobility where they were formed and thereby discouraging any migration away from the interface. The confinement of the RAFT polymerization close to the surface of the droplets successfully formed nanocapsules.

Shortly after this first successful report, Luo et al. envisaged the use of a macromolecular RAFT (macroRAFT) agent that could both act as a stabilizer of the droplets and help to localize the controlled polymerization at the surface of the monomer droplets. In a seminal work [36], they used a pre-formed RAFT copolymer of S and maleic anhydride (MAn) in the subsequent miniemulsion polymerization of S. The particularity of this co-monomer pair is that strictly alternating copolymers are obtained 
when identical molar amounts of $S$ and MAn are used. RAFT polymerization of $S$ and MAn was thus conducted in bulk to give P(S-alt-MAn) $\mathrm{m}$, which was then mixed with $\mathrm{S}$ and the templating liquid $\left(\mathrm{C}_{19} \mathrm{H}_{40}\right)$. This organic phase was dispersed in water containing ammonia, which aminolyzed the MAn units to hydrophilic carboxylate and amide groups. The resulting polymer chains migrated to the surface of the miniemulsion droplets where they assumed the role of reactive stabilizers capable of chain extension with $\mathrm{S}$ units in the droplets. The localization of these reactive stabilizers at the surface and the presence of the core material maintained the polymerization loci at the interface with water and allowed the inward growth of PS chains to generate nanocapsules. It is worth mentioning that the system did not provide capsule morphology quantitatively and a certain fraction of solid particles was also formed. Detailed investigation showed the importance of the hydrophilicity and the molar mass of the aminolyzed P(S-alt-MAn) chains in reducing the proportion of solid particles [37]. The minimum amount of solid particles was obtained when aminolysis of the pre-polymer was performed using an ammonia to anhydride ratio of 0.9 . Solid particles could be avoided under these conditions either by slightly increasing the number average molar mass of the P(S-alt$\mathrm{MAn}$ ) chains (from $1400 \mathrm{~g} \mathrm{~mol}^{-1}$ to $1795 \mathrm{~g} \mathrm{~mol}^{-1}$ ), or by the additional use of SDS as surfactant.

With the aim of producing capsules quantitatively, the same group further developed this interface-confined miniemulsion concept by employing poly(acrylic acid)- $b$-polystyrene (PAA- $b$-PS) block oligomers as reactive surfactants [38]. Miniemulsions of $S$ were prepared in water under alkaline conditions in the presence of a large amount of hexadecane (HD) as templating liquid. Although only very short block copolymers were attainable (containing on average only 2 AA units and from 1 to $3 \mathrm{~S}$ units per chain), surface tension measurements confirmed their surface activity and stable miniemulsions could be formed. Polymerizations were carried out with KPS as initiator. Upon polymerization, capsules were formed by chain extension of these oligomers located and maintained at the surface of the HD-rich monomer droplets. Control of the RAFT-mediated polymerization occurring in the majority of the particles was demonstrated by a linear increase in molar masses with conversion. An uncontrolled high molar mass population was also observed which the authors initially suspected to correspond to the small proportion of solid particles formed by homogeneous nucleation. The presence of these particles was attributed to the hydrolysis of some RAFT functionalities to produce chains which were no longer capable of chain extension, increasing the chance of homogeneous nucleation in which RAFT control is not imposed. This explanation was consistent with the higher-than-expected experimental molar mass values of the controlled polymer population, since fewer RAFT groups in the system would increase the average chain length at a given monomer conversion. The addition of SDS before sonication, keeping all else constant, suppressed the formation of the high molar mass population. Surprisingly, however, solid particles were still present, suggesting that the high molar mass polymer in the SDS-free system does not seem to originate from solid particles-further experiments are therefore required to explain its origin. The post-addition of a small fraction of SDS after 
miniemulsion formation was also studied and led to the generation of homogeneous capsules that could be separated by centrifugation from the unavoidable small amount of solid particles. In a similar study, the authors showed that the homogeneous nucleation could be attributed to the escape of the hydrophilic stabilizer-derived radicals from the surface of the droplets to the water phase [39].

\subsubsection{Shell-crosslinked nanocapsules}

On the strength of this new strategy to produce nanocapsules using RAFTsynthesized reactive stabilizers, the same group extended the interfacial RAFT miniemulsion polymerization idea to synthesize hollow nanoparticles exhibiting a crosslinked fluorinated shell [40]. Dodecafluoroheptyl acrylate (DFA) was miniemulsified in water in the presence of HD as hydrophobe, hexyl acetate as liquid core material, divinylbenzene (DVB) as crosslinker and AIBN as initiator. To stabilize the resulting droplets, low molar mass (1728 $\mathrm{g} \mathrm{mol}^{-1}, Ð=1.07$ ) poly(methacrylic acid)- $b$ poly(dodecafluoroheptyl acrylate) (PMAA- $b$-PDFA) block copolymers were first synthesized by RAFT using 4-cyano-4(dodecylsulfanylthiocarbonyl)sulfanylpentanoic acid (CDPA) as chain transfer agent. All the previous results of the authors were used here to prevent the formation of solid particles i.e. a low $\mathrm{pH}$ value (6.46) of the aqueous phase, use of a hydrophobic initiator (AIBN), addition of a radical scavenger in water $\left(\mathrm{NaNO}_{2}\right)$ and post-emulsification addition of a small amount of SDS. More than $95 \%$ of the particles obtained were nanocapsules and the gel content was measured to be $99 \%$, suggesting a high degree of crosslinking in the fluorinated shell. A control experiment was performed under the same conditions, but with PMAA- $b$-PDFA replaced by a corresponding amount of methacrylic acid (MAA). Solid particles were obtained. This result strongly suggests that the interfacial RAFT miniemulsion polymerization overcomes not only the kinetic but also the thermodynamic barriers to form welldefined core-shell structures. Hollow nanoparticles were obtained after removing the liquid core material by displacing it with tetrahydrofuran (THF) and drying the resulting dispersion.

Although not targeting nanocapsules, Jiang et al. employed a similar strategy to obtain shell-crosslinked nanoparticles using RAFT in miniemulsion [41]. Poly[2dimethylaminoethyl methacrylate) (PDMAEMA) was first synthesized by RAFT polymerization using CDPA as controlling agent. The presence of a long alkyl $\mathrm{Z}$ group in CDPA probably helped the resulting PDMAEMA-SC(=S)SC ${ }_{12} \mathrm{H}_{25}$ to be surface-active and to co-stabilize with cetyl trimethylammonium bromide (CTAB) a miniemulsion of $\mathrm{S}$ and bis-acryloyloxyethyl disulfide (BAEDS) as crosslinking comonomer. However, in this study, cyclohexane was used only as hydrophobe and thus in quantities lower than would have been required for it to act as a liquid core material. The authors claimed that shell-crosslinked nanoparticles were successfully obtained after initiating the polymerization with AIBN without clearly stating why the crosslinking reaction would only have occurred in the shell. 
ATRP has also been employed to design nanocapsules using miniemulsion polymerization [42]. The strategy was again based on the design of amphiphilic block copolymers that could be reactivated, in this case for the miniemulsion polymerization of an $n$-butyl methacrylate (BMA) dispersed phase. The positioning of these block copolymers at the surface of the monomer droplets forced the growth of the hydrophobic PBMA chains inwards, while the use of templating liquid-anisole and HD-confined the chains to the monomer droplet/water interface. The additional use of a crosslinker-either ethylene glycol dimethacrylate (EGDMA) or bis(2methacryloyloxyethyl)disulfide (DSDMA) - allowed crosslinking of the polymer chains to generate shell-crosslinked nanocapsules. The reactive stabilizers used in this system contained hydrophilic portions based on poly(ethylene oxide) (PEO): one in which PEO formed the main polymer chain, and one in which PEO formed the side chains. The latter was produced by polymerizing a PEO-based methacrylate monomer (PEOMA) using an azide-containing ATRP initiator, with the azide intended for post-functionalization of the final nanocapsules. Chain extension of both these PEO-based hydrophilic macroinitiators with BMA generated the reactive stabilizers denoted PEO- $b$-PBMA-Cl $\left(M_{\mathrm{n}}=12000 \mathrm{~g}\right.$ $\mathrm{mol}^{-1}, \oplus=1.15$ ) and $\mathrm{N}_{3}-\mathrm{P}(\mathrm{POEMA})-b$-PBMA-Cl [43] (molar mass characteristics not mentioned). Subsequent miniemulsion polymerization of BMA and the aforementioned crosslinkers using AGET ATRP produced several types of multifunctional capsules including degradable nanocapsules to which probes or other polymers could be clicked courtesy of their azide functionalities (Fig. 1).

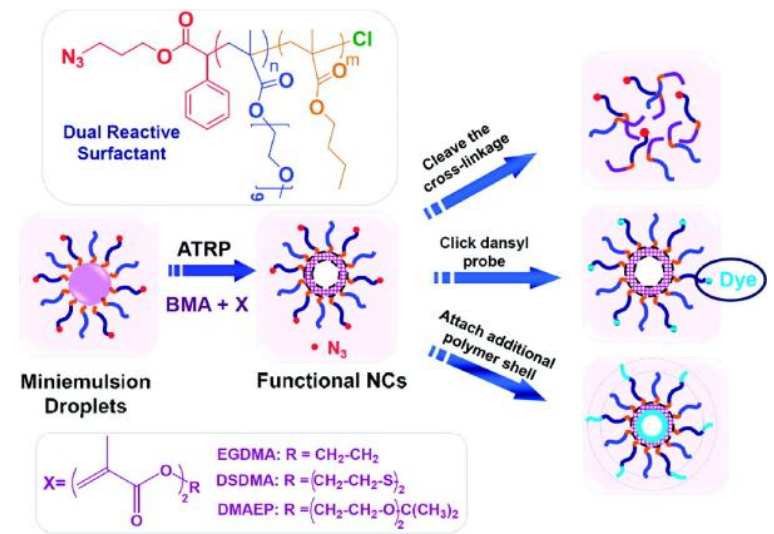

Fig. 1 Preparation of polymeric nanocapsules in miniemulsion using AGET ATRP and a mixture of dual and monofunctional reactive surfactants. Reproduced from [43] with permission from the American Chemical Society.

\subsection{Inverse miniemulsion}

The success of the RAFT-confined interfacial miniemulsion polymerizations described in the previous section was transposed to inverse miniemulsions with the aim of expanding the range of nanocapsules that could be synthesized. Lu et al. were the first in this pursuit, designing thermosensitive nanocapsules using a PEO-SC(=S)S- $\mathrm{C}_{12} \mathrm{H}_{25}$ trithiocarbonate as controlling agent [44]. $N$-isopropylacrylamide (NIPAM) as 
hydrophilic monomer was mixed with water as templating liquid, $\mathrm{PEO}-\mathrm{SC}(=\mathrm{S}) \mathrm{S}-\mathrm{C}_{12} \mathrm{H}_{25}$ as reactive stabilizer, VA044 as initiator and $\mathrm{Na}_{2} \mathrm{SO}_{4}$ as co-stabilizer. With the help of a nonionic commercial surfactant (B246SF from Uniquema), this solution formed a stable miniemulsion in cyclohexane, which was polymerized to form nanocapsules. Molar mass characterization of the polymer chains constituting these capsules confirmed successful chain extension of PEO-SC(=S)S- $\mathrm{C}_{12} \mathrm{H}_{25}$ with NIPAM under RAFT control. The same experiment was also conducted in absence of PEO-SC(=S)S- $\mathrm{C}_{12} \mathrm{H}_{25}$. Transmission electron microscopy (TEM) of the nano-objects produced in the two experiments showed that only the PEO-SC(=S)S- $\mathrm{C}_{12} \mathrm{H}_{25}$ system induced the interfacial miniemulsion polymerization to produce nanocapsules (Fig. 2). Dynamic light scattering (DLS) measurements performed at temperatures below and above the lower critical solution temperature of poly( $N$-isopropylacrylamide) (PNIPAM) demonstrated the thermosensitivity of the nanocapsules.

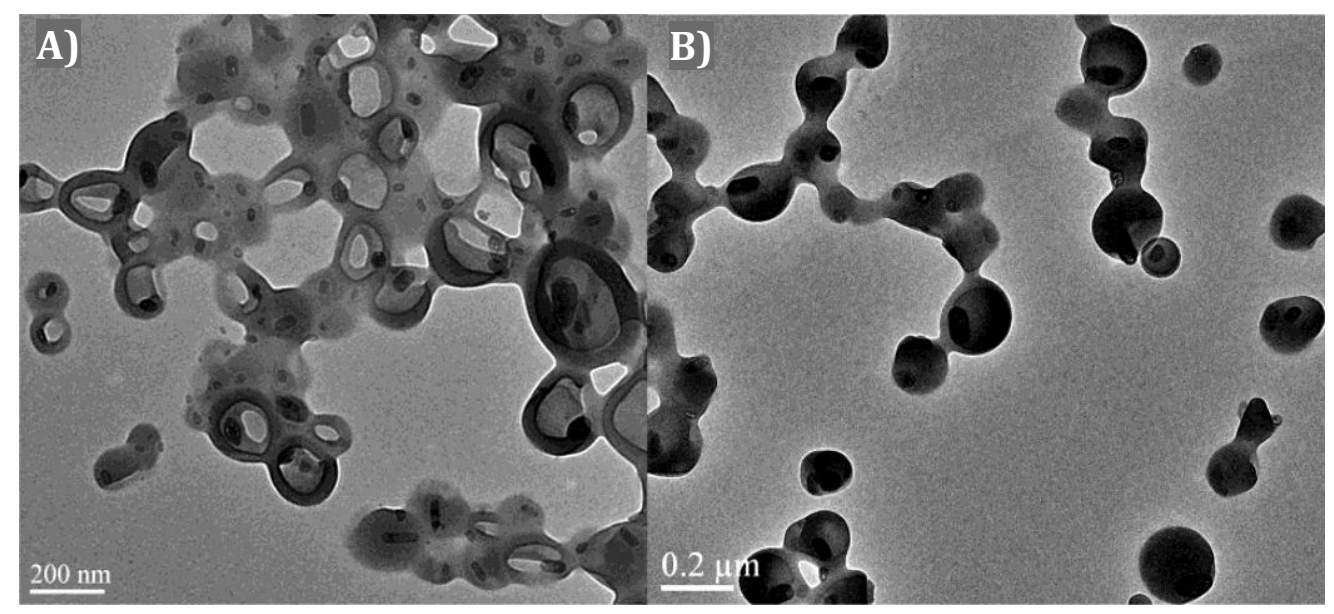

Fig. 2 TEM images for the latex obtained after: A) RAFT interfacial inverse miniemulsion polymerization of NIPAM; B) free radical inverse miniemulsion polymerization of NIPAM. Reproduced from [44] with permission from the American Chemical Society.

Wang et al. [45] demonstrated the versatility of the active stabilizer PDMAEMA$\mathrm{SC}(=\mathrm{S}) \mathrm{S}-\mathrm{C}_{12} \mathrm{H}_{25}$ used in their previous work [41] by employing it for the inverse miniemulsion polymerization of MAA and BAEDS (crosslinker) in cyclohexane to produce hydrophilic shell-crosslinked nanocapcules. Ammonium persulfate, MAA and PDMAEMA-SC $(=\mathrm{S}) \mathrm{S}-\mathrm{C}_{12} \mathrm{H}_{25}$ dissolved in water were added to a continuous phase composed of cyclohexane, Span 80 used as surfactant and BAEDS used as cleavable crosslinking comonomer. A stable miniemulsion was obtained after sonication, and polymerization generated shell-crosslinked nanocapsules. It is very interesting that successful crosslinking was achieved even when the crosslinker did not reside with the MAA monomer in the hydrophilic dispersed phase. This was made possible by the confinement of the PDMAEMA-SC(=S)S- $\mathrm{C}_{12} \mathrm{H}_{25}$ reactive stabilizers at the interface, which meant that the propagating species were generated very close to the interface and could therefore react with both MAA units from the water phase and crosslinker units from the continuous phase. 
Utama et al. [46] recently proposed an alternative strategy to prepare nanocapsules using RAFT polymerization in an inverse miniemulsion system. In this approach, dispersed aqueous droplets (with RAFT-based active stabilizers at their interface) simply acted as templates, and chain extension with hydrophobic monomers and crosslinkers contained in the surrounding continuous phase yielded the nanocapsules. More specifically, methyl methacrylate (MMA) [46] or S [47], crosslinker (EGDMA or DVB, respectively), and initiator (AIBN) were dissolved in a toluene continuous phase. Water droplets containing sodium chloride as lipophobe were formed in these toluene solutions and stabilized with RAFT-synthesized poly $(\mathrm{N}-2$ (hydroxypropyl methacrylamide))- $b$-poly(methyl methacrylate) (PHPMA- $b$-PMMA) or PHPMA- $b$-PS block copolymers, where the PHPMA segment is hydrophilic. The subsequent polymerization was confined to the periphery of the water droplets to generate the nanocapsules. The styrene system (which attained $17 \%$ conversion in $24 \mathrm{~h}$ ) was complicated by some coalescence and solid particle formation [47]. In the case of MMA [46,47], conversion reached $51 \%$ in $7 \mathrm{~h}$ without any noticeable change in turbidity or viscosity, implying that the features of the original miniemulsion were preserved. Conversions higher than $51 \%$ led to an increase in viscosity associated with the onset of interparticle crosslinking. A good correlation between the starting water droplet size $(170 \mathrm{~nm})$ and the final capsules size $(220 \mathrm{~nm})$ was observed by DLS as expected for a miniemulsion polymerization process. The desired shell-crosslinked hollow nanoparticles were clearly revealed by TEM (Fig. 3), confirming the effectiveness of the synthetic strategy. The successful encapsulation and release of bovine serum albumin in the aqueous core were also demonstrated with no detrimental denaturation of the protein occurring during the synthesis.

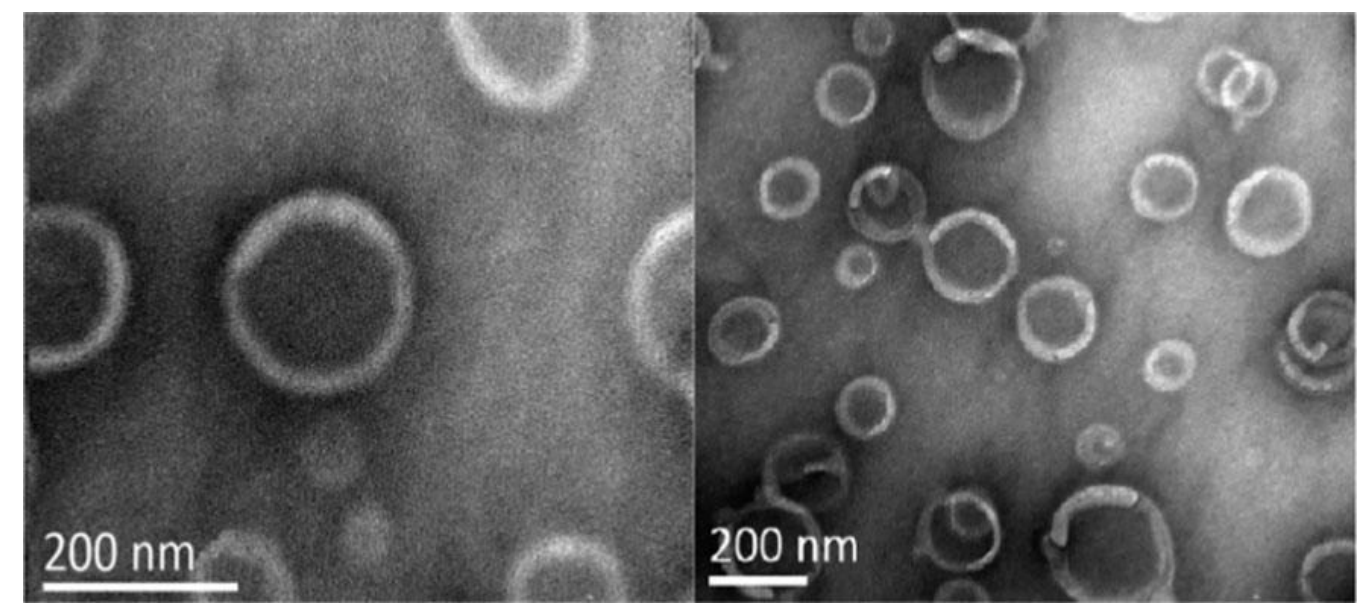

Fig. 3 TEM images of hollow nanoparticles synthesized via RAFT inverse miniemulsion periphery polymerization of MMA and EGDMA. Reproduced from [46] with permission from the Royal Society of Chemistry.

This novel strategy, coined inverse miniemulsion periphery polymerization (IMEPP) based on previous works of Wang et al. [48], is a valuable one-pot alternative to the nanocapsule syntheses described earlier. One of its significant advantages is the 
location of the RAFT functionality at the periphery of the final objects, which can be taken advantage of to perform further functionalization. This was indeed evaluated when the same authors targeted pH-responsive nanocapsules by IMEPP [49].

\subsection{Vesicle-templated controlled radical polymerization: an alternative to miniemulsion}

Colloidal templating is an alternate route for the synthesis of nanocapsules, in which CRP also plays a pivotal role. The technique involves the electrostatic deposition of charged RAFT polymers onto vesicles (which display the opposite charge), followed by emulsion polymerization to generate a hydrophobic polymer shell (Fig. 4). This approach, first reported by Ali et al. [50], is conceptually identical to Hawkett's strategy for encapsulating charged inorganic particles [51] as described in section 4.2.

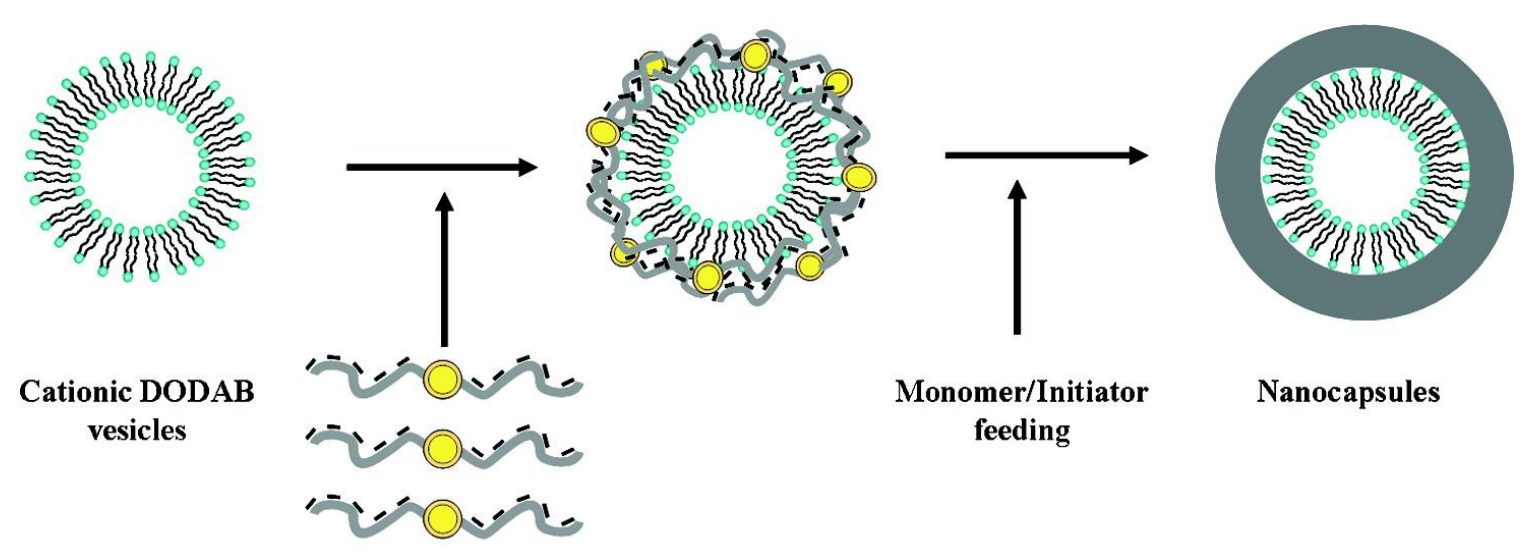

Anionic RAFT copolymers

Fig. 4 Schematic representation of the synthesis of vesicle-templated nanocapsules by aqueous starve-feed emulsion polymerization using RAFT copolymers as stabilizers. Reproduced from [50] with permission from the American Chemical Society.

The first report investigated the adsorption of $\mathrm{P}(\mathrm{AA}-\mathrm{Co}-\mathrm{BA})$ obtained by dibenzyl trithiocarbonate (DBTTC)-mediated RAFT copolymerization onto cationic vesicles formed from the double-chain cationic surfactant dimethyldioctadecyl ammonium bromide (DODAB). To obtain large unilamellar vesicles, a membrane extrusion method was employed, giving vesicles of around $130 \mathrm{~nm}$. Three negatively-charged copolymers with varying AA/BA compositions $(9 / 6,10 / 3,4 / 6)$ were then adsorbed onto the positively-charged vesicles. A careful study by zeta potential measurements and size analyses showed that the adsorption can be controlled in the range above the charge inversion of the starting vesicles.

Encapsulations were performed by starve-feed emulsion polymerization of a MMA/BA monomer mixture (molar ratio of 10/1). Polymerization commenced at the vesicle surface courtesy of the active RAFT end groups of the adsorbed polymer chains, generating a hydrophobic polymer shell. The strategy was extended to the design of $\mathrm{pH}-$ 
responsive polymeric capsules by incorporating a crosslinker (EGDMA, from 3 to 10 mol\%) into the MMA/tert-butyl acrylate ( $t$-BA) monomer feed [52]. The high stability of the crosslinked nanocapsules was confirmed by surfactant lysis experiments using Triton X-100, a non-ionic surfactant known for its excellent membrane destabilizing properties, using turbidity measurements. Increasing the crosslinker content in the monomer feed led to polymer segregation (shown by TEM in Fig. 5d, left) rather than a uniform polymer shell. A high concentration of crosslinker increased the likelihood of forming highly branched polymer at a very early stage of the polymerization, restricting the diffusion of both the polymer chains and the monomer on the polymerization locus. Selective cleavage of the tert-butyl ester groups in the final nanocapsules using anhydrous trifluoroacetic acid (TFA) in dioxane converted the $t$-BA units to AA units, affording $\mathrm{pH}$-responsive particles with smoother surfaces than the pristine nanocapsules (shown by TEM in Fig. 5, right). The pH-responsiveness of these capsules was demonstrated by their swelling or contraction upon variations of the $\mathrm{pH}$ value.
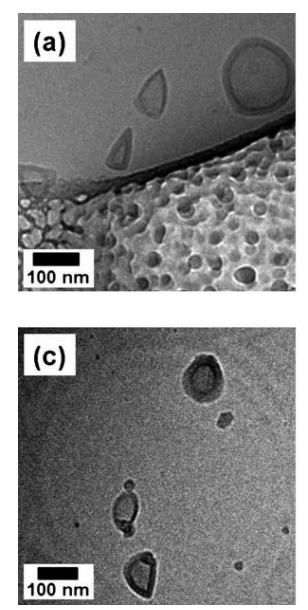
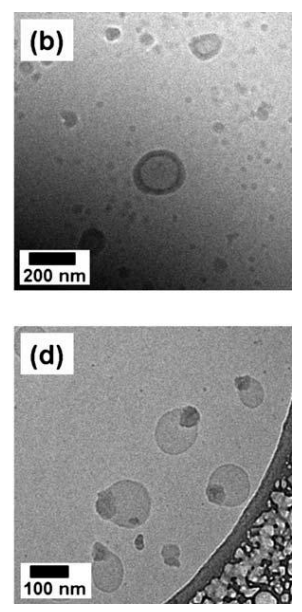
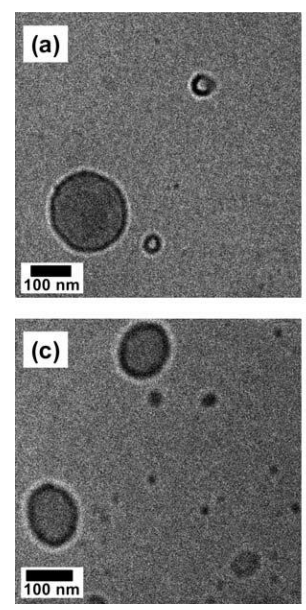
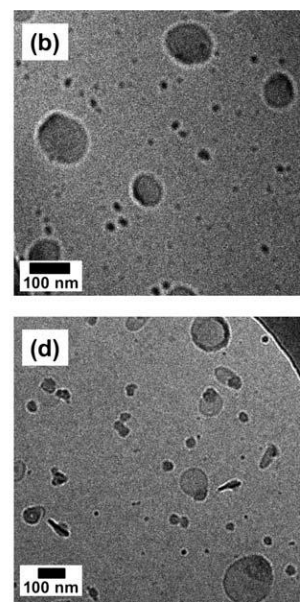

Fig. 5 Cryo-TEM micrographs of crosslinked nanocapsules. Left: Nanocapsules obtained by encapsulating DODAB vesicles (obtained by extrusion through $100 \mathrm{~nm}$ pore size filters) using RAFT copolymer $\mathrm{P}\left(\mathrm{BA}_{6}-\mathrm{Co}-\mathrm{AA}_{9}\right)$ and MMA:t-BA:EGDMA monomer at molar feed ratios of (a) 2:1:0.14, (b) 1:2:0.1, (c) 1:2:0.16 and (d) 1:2:0.33. Right: Crosslinked P(MMA-co-AA) nanocapsules obtained after acid hydrolysis of the same four crosslinked P(MMA-co-t-BA) nanocapsules shown at left. Sample vitrification was performed at $\mathrm{pH}=7.2$ in liquid ethane. Reproduced from [52] with permission from the Royal Society of Chemistry.

\section{SYNTHESIS OF POLYMER/INORGANIC COMPOSITE PARTICLES}

(Mini)emulsion polymerizations have naturally emerged as methods of choice to generate a broad range of composite organic/inorganic colloids that, depending on the field of application, can be either used directly as dispersions or be further processed into films with improved mechanical, thermal or barrier properties compared to the corresponding films without inorganic component. In this regard, mastering the size, shape and morphology of composite particles is key in controlling the final material properties. In that respect, CRP appears as a very powerful tool to increase further the 
design of such particles. Section 4.1 will detail the most recent works relying on the use of CRP in miniemulsion polymerization for the preparation of composite colloids, whereas emulsion polymerization-based strategies will be described in section 4.2. In many cases CRP enables the access to morphology that could not be attained using conventional free radical polymerization. In the case of emulsion polymerization, it also brings the additional advantage of carrying out the polymerization in absence of any molecular surfactant, which can have detrimental effects on the properties of the final material.

\subsection{Miniemulsion polymerization approaches}

As mentioned in the introduction, the intrinsic features of miniemulsion can be taken advantage of for the incorporation of inorganic materials $[14-17,12,18]$, the success of the reaction relying on a good dispersibility of the inorganic particles in the monomer droplets before the beginning of the polymerization. Indeed, in most cases, these particles typically tend to be hydrophilic whereas the monomer droplets (and later on the polymer particles) are hydrophobic, which prevents a direct interaction and makes a pretreatment of their surface with compatibilizers indispensible. CRP techniques can be an efficient tool in the development of successful miniemulsion polymerization approaches for the synthesis of polymer/inorganic composite particles. Various strategies can be envisioned. The first one consists in the modification of the inorganic particle, either with inactive hydrophobization species or with molecules involved in the CRP process (i.e. immobilized monomers or controlling agents). These surface-active particles can then be used in bulk or solution polymerization to grow polymer chains from their surface and the resulting polymer-decorated inorganics can then be used in miniemulsion polymerization. A more straightforward method, however, consists in directly using the surface-active particles (if organosoluble) in the miniemulsion process. These different approaches have been explored using the main CRP techniques (i.e. NMP, ATRP and RAFT) and they will be detailed in the following sections, arranged according to the type of the inorganic particle used.

\subsubsection{Silica}

NMP, (AGET) ATRP and RAFT have all been used for the synthesis of silica-based composite latexes. Bailly et al. [53] were the first to report the use of CRP to grow PS chains from the surface of $80 \mathrm{~nm}$ silica particles previously modified by the adsorption of an alkoxyamine derived from $N$-tert-butyl- $N$-[1-diethylphosphono-(2,2-dimethylpropyldimethylpropyl)] nitroxide (SG1). The obtained PS-covered silica particles were then efficiently dispersed in S droplets yielding silica/PS core-shell particles after miniemulsion NMP. In a later experiment, AGET ATRP was successfully implemented for the miniemulsion polymerization of BA droplets containing $20 \mathrm{~nm}$ silica particles modified by 1-(chlorodimethylsilyl)propyl 2-bromoisobutyrate (Bombalski et al. [54]). Hereby, $\mathrm{CuBr}_{2}$ and the amino-ligand bis(2-pyridylmethyl)octadecylamine were first mixed with silica and $\mathrm{BA}$ to generate the $\mathrm{Cu}$ (II) complexes. After addition of Brij 98 
(surfactant), HD (costabilizer) and water, the miniemulsion was generated by sonication. Ascorbic acid (reducing agent) was finally added to start the polymerization. A conversion of $70 \%$ was reached in $20 \mathrm{~h}$, providing a stable latex composed of composite particles with diameters of approximately $220 \mathrm{~nm}$, each one incorporating an average of 75 silica particles. The control of the polymerization was satisfactory, with a relatively good agreement between theoretical and experimental molar masses indicating a high initiation efficiency. Atomic force microscopy (AFM) of the hybrid particles after drying and redispersing in THF showed the formation of the expected silica/poly(n-butyl acrylate) (PBA) core-shell particles (Fig. 6). Compared with the analog bulk experiment, the miniemulsion process allowed the preparation of such hybrid materials with a higher yield (because of a higher conversion) and a higher polymerization rate without the macroscopic gelation usually observed in bulk polymerizations, which is associated with interparticle coupling.

In both the NMP and the AGET ATRP studies, CRP was used to grow polymer chains from the silica surface and thus to provide a good compatibility of these modified particles with the monomer phase for the subsequent miniemulsion polymerization. In the next example describing the formation of silica/PMMA composite particles by RAFT mediated miniemulsion polymerization [55], the pursued strategy was different. After modification of the silica surface with a polymerizable silane (3-methacryloxypropyl trimethoxysilane), MMA miniemulsion polymerization was performed in the presence of an organosoluble trithiocarbonate RAFT agent, namely 2-([Ctertbutylsulfanyl)carbonothioyl]sulfanyl) propanoic acid. The good agreement between theoretical and experimental molar masses and the low dispersities attested for a good control of the polymerization. Increasing the silica content led to decreased monomer conversions (and consequently to lower molar masses). Despite thermal analyses indicating positive effects of silica on the thermal stability of the formed nanocomposites, TEM images did not clearly show the final particle morphologies. Not even the presence of the silica particles could be proven with this method. The very same study was then performed without preceding surface modification of the silica [56]. The overall conclusions were basically the same. The authors mentioned in this second work the possible location of the silica nanoparticles at the PMMA particle/water interface, however without providing clear explanations. In both studies, there was no comment on the initial state of the systems that could clarify whether the polymerization actually proceeded according to a miniemulsion process. 


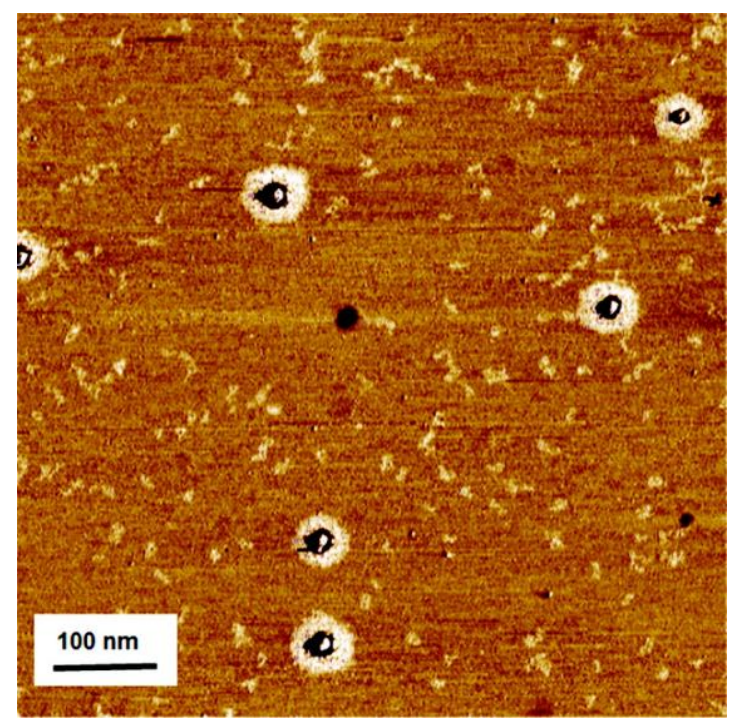

Fig. 6 AFM image of silica/PBA nanoparticles prepared by AGET ATRP in miniemulsion. The hybrid nanoparticles were collected by redispersing the dried miniemulsion samples in THF before subjecting the dispersion to AFM characterization. Reproduced from [54] with permission from the American Chemical Society.

\subsubsection{Montmorillonite (MMT)}

Following an NMP-based approach similar to the one mentioned above for silica by Bailly et al. [53], Mičušík et al. [57] have prepared montmorillonite (MMT)/P(BA-coMMA) composite latexes (Fig. 7). A cationic macroalkoxyamine based on vinylbenzyl trimethylammonium chloride (VBTMACl), MMA and S (P(VBTMACl-co-MMA7-Co-S H $_{4}$, $\mathrm{N}^{+} \mathrm{M}$ in Fig. 7) was prepared using the BlocBuilder ${ }^{\circledR}$ alkoxyamine, and then exchanged with the sodium cations of MMT ( $-\mathrm{N}^{+} \mathrm{M}$ in Fig. 7). Copolymerization of BA and MMA was then performed in bulk in the presence of the modified MMT with a limited control over the molar masses, nevertheless leading to the formation of exfoliated clay sheets decorated with polymer chains. This polymer/clay composite was then dispersed in BA/MMA droplets using stearyl acrylate as a hydrophobe and Dowfax 2A1 (alkyldiphenyloxide disulfonate) as a surfactant. Miniemulsion polymerization was then initiated by addition of KPS, yielding a stable latex able to form nanocomposite films which incorporated exfoliated clay platelets and showed improved adhesive properties compared to the neat polymer. In comparison, the use of MMT which had been only modified by the cationic macroalkoxyamine and without prepolymerization did not lead to a stable latex, showing the crucial role of the grafted P(BA-co-MMA) chains in ensuring a good dispersibility and compatibility of MMT with the polymer matrix. 

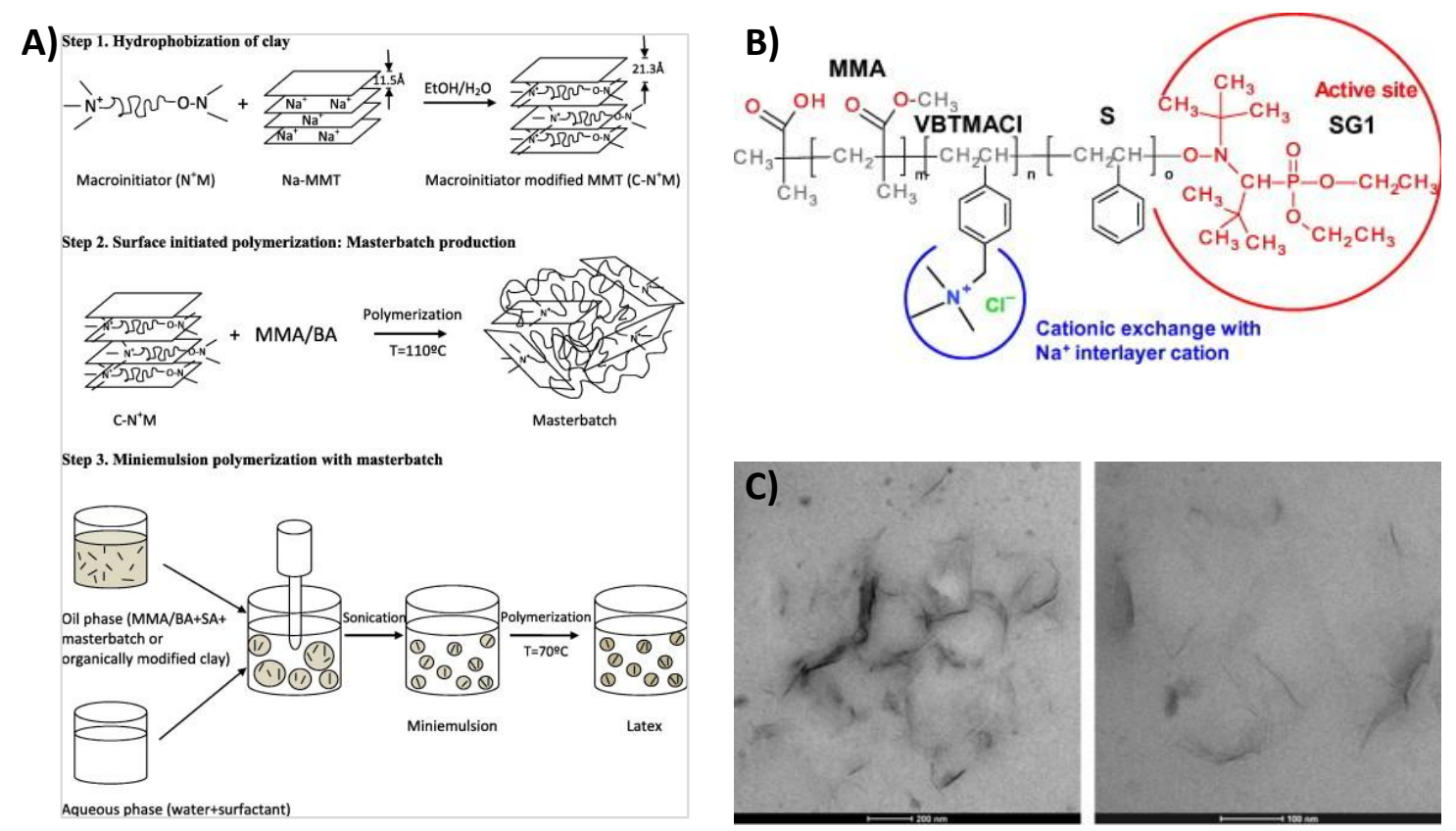

Fig. 7 Synthesis of MMT/P(BA-co-MMA) composite latexes. A) Schematic representation of the synthetic procedure followed to produce waterborne acrylic/clay nanocomposites. B) Chemical structure of the macroinitiator containing a quaternary ammonium salt $\left(\mathrm{N}^{+} \mathrm{M}\right)$ used to modify Na-MMT. C) TEM pictures of a film prepared with P(BA-co-MMA)/C-N+M masterbatch and KPS. Reproduced from [57] with permission from Elsevier.

Khezri et al. [58] used AGET ATRP to prepare P(S-co-MMA)/MMT nanocomposites. The commercial organomodified MMT was dispersed in monomer droplets with a diameter of approximately $200 \mathrm{~nm}$. The system also contained ethyl $\alpha$ bromoisobutyrate (EBiB), the ligand 4,4'-dinonyl-2,2'-bipyridine ( $\mathrm{dNbPy}), \mathrm{CuBr}_{2}, \mathrm{HD}$ and CTAB as the stabilizer (less temperature-sensitive than the commonly used Brij 98). The polymerization was started by addition of ascorbic acid and led to the formation of polymer/MMT composite particles. Increasing the amount of clay (from 0 to $2 \mathrm{wt} \%$ ) induced a decrease of both conversion and molar masses and yielded broader molar mass distributions. According to the authors, this could be ascribed to the partitioning of $\mathrm{CuBr}_{2}$ (deactivator) between the different phases and a high concentration of ascorbic acid. In addition, the clay platelets could also hinder the diffusion of the monomer, the initiator and the metal complex, and promote irreversible chain transfer and termination reactions. Nevertheless, the presence of clay improved the nanocomposites' thermal stability. Exfoliated platelets well dispersed in the polymer matrix were found. In a very similar study conducted by the same authors using reverse ATRP [59] comparable nanocomposites were obtained. The strategy was later on repeated for $\mathrm{S}$ with reverse ATRP [60], and for MMA with simultaneous reverse and normal initiation (SR\&NI) ATRP [61]. The same team also prepared P(S-co-BA)/MMT composite latexes by both miniemulsion AGET ATRP [62] and miniemulsion reverse ATRP [63]. On the whole, they noticed the same effect of clay content on conversion, molar masses and 
thermal stability, even if the clay sheets were in some cases only partially delaminated owing to the lower molar masses of the polymer chains [62]. A deeper kinetic and mechanistic investigation of this AGET ATRP system was later reported [64]. It is worth noting that in all these works, ATRP was used to grow polymer chains in the vicinity of the MMT platelets but not from their surface, since the platelets did not carry any functionalities participating in the ATRP process.

The first report on the use of the RAFT technique for the preparation of composite latexes in a miniemulsion system can likely be attributed to Samakande et al. who described the encapsulation of MMT clay inside PS [65] or P(S-co-BA) [66] particles. Similar observations were made for both systems in which MMT platelets modified with anchored cationic (ammonium bromide-type) RAFT agents (dithiobenzoate or trithiocarbonate, respectively) were readily dispersed in the monomer droplets. SDS and HD were used to stabilize the system and AIBN as the initiator. Monomer conversion decreased with increasing clay loading. As expected, due to the compartmentalization effect, the conversion was however systematically higher than that obtained in analogous bulk experiments [67]. While the control over the molar masses of the produced polymers was reasonably good in both systems, the trithiocarbonate-based system provided a better polymerization control of the two. Molar masses and dispersities both decreased as the amount of clay increased, owing to a higher concentration of RAFT agent. The discrepancy between theoretical and experimental molar masses was attributed to the lower controlling ability of anchored RAFT agents compared with RAFT agents in solution. The sizes of the droplets were not reported, but the diameter of the final clay-loaded particles increased with the amount of clay. The platelets could only be visualized with conventional TEM after being embedded in an epoxy resin. Small-angle X-ray scattering (SAXS) analyses also confirmed their presence. The platelets showed a partially exfoliated morphology that evolved into an intercalated one as the clay loading increased, in accordance with the simultaneously growing molar masses of the polymer chains. The thermo-mechanical properties of the resulting nanocomposites depended on the molar masses and the dispersities of the polymer chains, the clay loading and the platelet morphology (i.e. partially exfoliated versus intercalated).

\subsubsection{Quantum dots (QDs)}

A system similar to that developed for silica by Bombalski et al. [54] (see above) was used by Esteves et al. [68] to form cadmium sulfide (CdS) quantum dot (QD)/PBA composite particles by miniemulsion AGET ATRP (Fig. 8, left). The QDs were first functionalized with trialkylphosphine ligand molecules carrying chlorine-based ATRP initiator groups. This step slightly affected the size and consequently the optical properties of the QDs. After $24 \mathrm{~h}$ of miniemulsion polymerization, a stable latex was obtained. The size of the resulting latex particles was not mentioned, but the diameter of the core-shell QD/PBA particles observed by AFM after dispersion in THF was estimated to be close to $100 \mathrm{~nm}$. A good control over the growth of the PBA chains was 
achieved. This approach allowed preservation of the optical properties of the QDs by avoiding the use of conventional radical initiators, which can lead to extensive degradation of the QDs. Following on from this study, Esteves et al. [69] prepared CdS or CdSe QD/PS nanocomposites using the RAFT technique (Fig. 8, right). The QD surface was first functionalized with a trialkylphosphine oxide bearing the RAFT-active 4-cyano4-(thio-benzoylsulfanyl)pentanoic acid moieties. The resulting hydrophobic nanoparticles could be well dispersed in S. Miniemulsion polymerization resulted in the formation of QD-tagged PS particles (along with a not quantified, but minor fraction of free PS particles). The QDs, encapsulated in the PS particles as small clusters, preserved their optical properties (aside from a slight blue-shift of the onset of the absorption signal) proving that the integrity of the nanocrystals had been maintained.
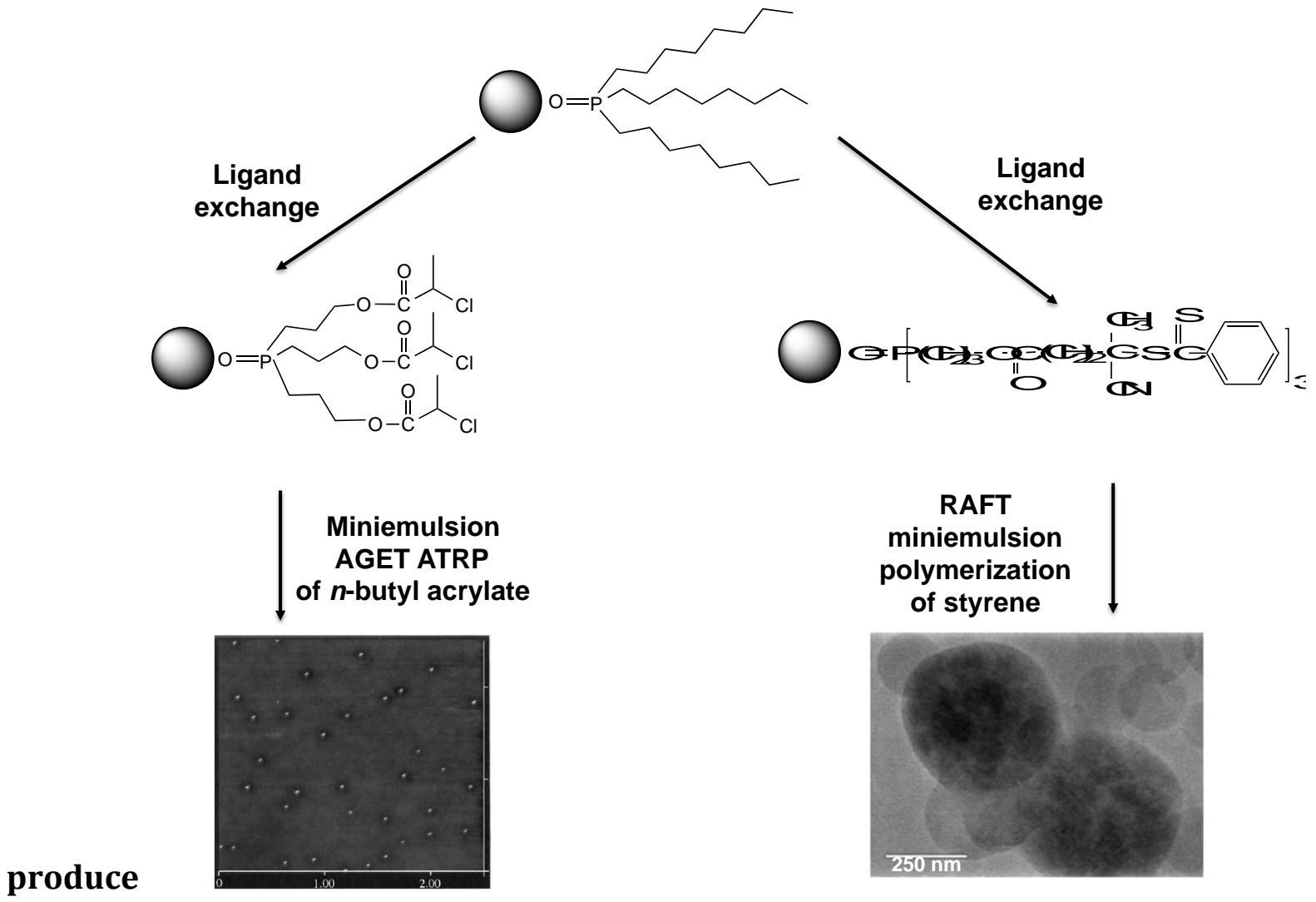

Fig. 8 Synthesis of QD/polymer composite latexes. Schematic representation of the synthetic procedures followed to either QD/PBA latexes through AGET ATRP in miniemulsion [68] (left, inlay shows tapping-mode AFM image, $2.5 \mu \mathrm{m} \times 2.5 \mu \mathrm{m}$ ) or QD/PS latexes through RAFT miniemulsion polymerization [69] (right, inlay shows TEM image). Reproduced and adapted from [68] and from [69] with permission from Wiley-VCH.

\subsubsection{Magnetic nanoparticles (MNPs)}

Despite the widespread interest in the synthesis of magnetic polymer latexes, Chakraborty et al. have recently been the first to report a RAFT mediated miniemulsion polymerization approach [70] (Fig. 9) involving magnetic iron oxide nanoparticles. In addition, their study is also the first work describing the use of amphiphilic ionic liquids (1- $N$-alkyl-3-methylimidazolium bromide-type) as surfactants. In spite of the known 
incompatibility of oleic acid (OA) and PS, OA-coated MNPs were used in this study. The employment of these MNPs in a conventional miniemulsion polymerization systematically led to phase separation between PS and the MNPs inside the particles (Janus-type morphology, Fig. 9B), most of the times accompanied by a low stability of the resulting latexes and the formation of empty PS particles. Capitalizing on the known affinity of carboxylic acid groups for the surface of MNP, another series of miniemulsion experiments was then undertaken using an organosoluble symmetrical trithiocarbonate RAFT agent which carried carboxylic acid groups (2,2'-[carbonothiobis(thio)]bis(2methylpropionic acid)). A fine-tuning of the molar ratio of AIBN and the RAFT agent and varying the final conversion allowed the formation of relatively stable PS particles incorporating up to $27 \mathrm{wt} \%$ (with respect to polymer) of MNPs which imparted their special magnetic properties to the composite products (saturation magnetization $M_{\mathrm{s}}$ of $16.6 \mathrm{emu}^{-1}$ for the sample with the highest value). The molar ratio of AIBN and the RAFT agent also strongly impacted the final particle morphology, which was either a homogeneous distribution of the MNP within the PS particles (Fig. 9C) or again of Janustype (Fig. 9D). In all cases, no empty PS particles were found. The synthesis of magnetic composite particles was also recently reported by $\mathrm{Gu}$ et al. [71]. Taking advantage of their recent $\mathrm{Fe}(0)$ mediated RAFT technique [72], crosslinked P(MMA-co-EGDMA) particles incorporating $\mathrm{Fe}(0)$ nanoparticles were obtained. The magnetic properties of the final particles were however only very weakly pronounced $\left(M_{\mathrm{s}}\right.$ lower than $0.1 \mathrm{emu}$ $\left.\mathrm{g}^{-1}\right)$.

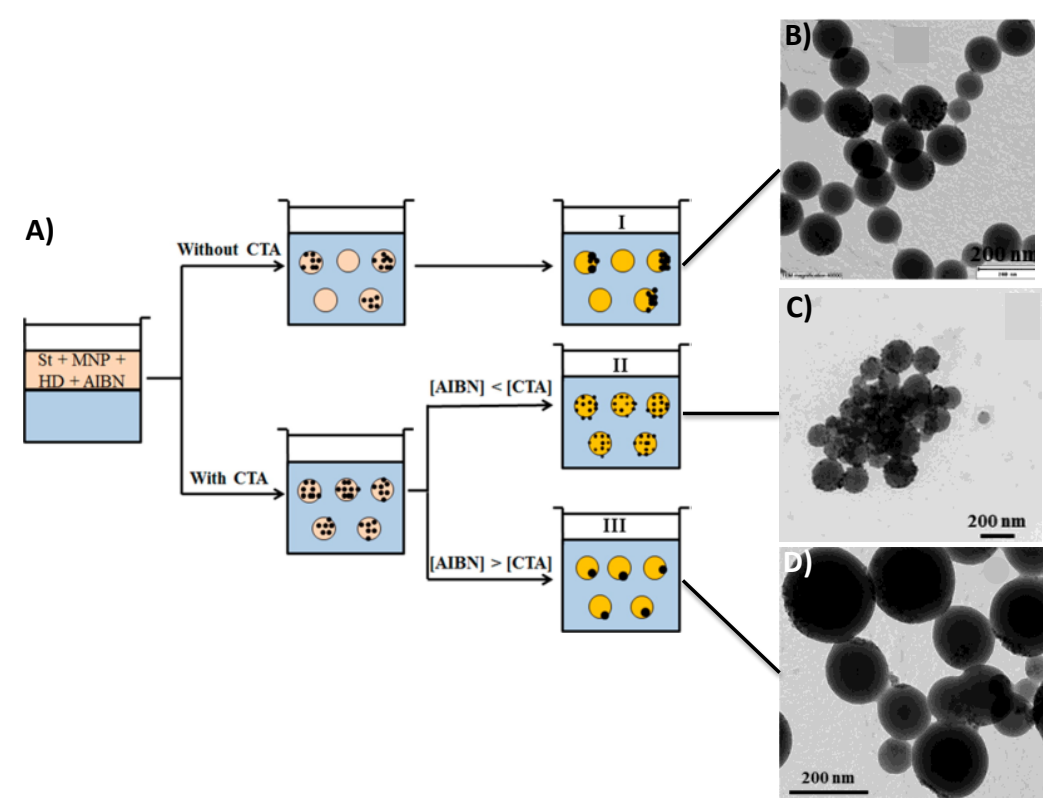

Fig. 9 Synthesis of PS particles containing magnetic iron oxide nanoparticles via polymerization in a miniemulsion system stabilized by amphiphilic ionic liquids. A) Schematic representation of the different accessible morphologies and the corresponding synthesis pathways. B) TEM image of the particles formed using conventional miniemulsion polymerization. C) TEM image of the particles obtained by RAFT mediated miniemulsion polymerization showing a homogeneous distribution of the MNPs within the PS particles. D) TEM image of the particles obtained by RAFT mediated miniemulsion polymerization with a significantly higher amount of initiator leading to an anisotropic distribution of MNPs (Janus-like morphology). Reproduced from [70] with permission from the American Chemical Society. 


\subsubsection{Graphite oxide}

In a last study that should be included here, PS particles containing graphite oxide (GO) sheets were prepared via RAFT mediated miniemulsion polymerization [73]. As a matter of fact, GO is technically not an inorganic compound, but its encapsulation involves concepts similar to the ones described above. The carboxyl-group bearing RAFT agent dodecyl isobutyric acid trithiocarbonate (DIBTC) was first attached to the GO sheets via the esterification reaction to their hydroxyl groups. To enable the dispersion of the GO-DIBTC nanoplatelets in $\mathrm{S}$ and the formation of stable miniemulsions, several experimental steps were required: i) dispersion of DIBTCdecorated GO in water under sonication; ii) addition of S, AIBN and HD followed by stirring and sonication of the mixture; iii) addition of an aqueous solution of sodium dodecylbenzene sulfonate (SDBS) followed by stirring and sonication of the mixture. Different miniemulsion polymerizations were then performed using various amounts of DIBTC-covered GO (up to $7 \mathrm{wt} \% /$ monomer). Stable latexes were obtained, the particle diameter increasing with the GO content from 125 to $160 \mathrm{~nm}$ (DLS). As expected, an increase of the grafting density of DIBTC on the GO (i.e. an increasing RAFT agent concentration) led to lower molar masses of the resulting polymer chains with narrower distributions. The GO sheets could not be visualized directly via TEM of the obtained particles but could be identified after embedding the dried latex in an epoxy resin. Most of the graphite nanoplatelets were of exfoliated morphology with a few intercalated nanosheets. This structure was additionally confirmed by X-ray diffraction measurements. In the final analyses, the GO/PS nanocomposites showed enhanced mechanical properties and thermal stability compared to neat PS.

\subsection{Emulsion polymerization approaches}

Emulsion polymerization has several advantages over miniemulsion polymerization. In particular, it neither requires any energy-consuming high shear devices to create the miniemulsion droplets nor the presence of additional additives such as hydrophobic costabilizers. Among the most important features of emulsion polymerization is the ability to control the particle morphology (e.g., formation of coreshell particles and other equilibrium morphologies), by successive addition of different monomers in the presence of preformed organic or inorganic particles. Within the last twenty years, there has been an increasing interest in the synthesis of polymeric/inorganic materials by emulsion polymerization and the reader is referred to a number of recent comprehensive reviews [5-7].

As mentioned in the introduction, physical or chemical methods can be employed to encapsulate inorganic particles in emulsion polymerization. Although the chemical approach has been successful in a number of cases, it frequently entails inherent experimental problems such as loss of colloidal stability, formation of secondary nucleated particles devoid of inorganic component, incomplete encapsulation of the inorganic particles accompanied by the formation of hemispherical or other anisotropic 
structures, and lack of reproducibility. In addition, this strategy often requires timeconsuming chemical modification reactions of the particle surfaces that do not always lead to the desired morphologies. With the recent developments in the field of CRP techniques in aqueous media, new approaches to obtain hybrid latexes with different particle morphologies have been made feasible, opening up new and promising pathways for the synthesis of colloidal nanocomposites. An overview of these methods is given in the following sections. It should be noted that among the various CRP techniques, RAFT-mediated processes have been almost exclusively reported until now with the exception of one example involving NMP.

\subsubsection{MacroRAFT-assisted encapsulating emulsion polymerization (REEP)}

In the last two decades, CRP techniques have been extensively used to generate a large variety of organic/inorganic hybrid morphologies like Janus-, core-corona-, and core-shell nanoparticles as well as several types of anisotropic particles. This could be achieved using grafting-from, grafting-to or self-assembly techniques [74-78]. These techniques usually involve surface modification (by covalent linking or via physisorption) of preformed inorganic particles with copolymers (synthesized by CRP) in organic solvents, and subsequent solvent evaporation or solvent displacement to recover the hybrid particles prior to their application for which often water-based systems are needed. However, since January 2000, the use of volatile organic compounds has been severely restricted by law and coating formulators are progressively switching from solvent-borne processes or products to safe waterborne alternatives. In parallel, striking progress has been made in the development of CRP in dispersed systems and an extensive range of monomers can nowadays be polymerized using CRP methods in aqueous systems. Controlled and well-defined polymer particles can thus be obtained [79]. Taking advantage of these advances, the implementation of CRP in emulsion polymerization has been developed as an innovative route to generate a variety of organic/inorganic composite particles [80]. Among them, core-shell particles where the core is an inorganic particle and the shell composed of a polymer have attracted particular attention [81]. The shell can protect the core from extraneous physical or chemical changes and can enhance the compatibility between the inorganic filler and the polymer matrix. Alternatively, the core can also be an organic pigment. Core-shell particles are currently of interest for a wide variety of applications, including applications in emulsion paints, in optics and biology.

The first reports of CRP-mediated encapsulating emulsion polymerization were published almost simultaneously by Nguyen et al. [51] and Daigle et al. [82]. These authors developed a simple and versatile method allowing the efficient encapsulation of both organic and inorganic particulate materials via free-radical polymerization in aqueous dispersed media. In short, the method uses living amphiphilic random copolymers, which can adsorb on the core particles leading the emulsion polymerization to occur at their surface as illustrated schematically in Fig. 10. These copolymers are 
synthesized via RAFT polymerization and thus possess a RAFT functionality on one extremity which is able to be reactivated for the polymerization of hydrophobic monomers. In addition, the relatively high hydrophilicity of the macroRAFT agents provides stability for the aqueous dispersion of nanoparticles before the polymerization, and participates to the stability of the final encapsulated particles. The overall process involves two steps: i) macroRAFT agent adsorption on the surface of the inorganic particles in aqueous suspensions, and ii) emulsion polymerization of hydrophobic monomers in batch or under starve-feed conditions where the macroRAFTfunctionalized particles act as seeds for the nucleation process. The presence of the living copolymers on the particle surface facilitates rapid transfer of hydrophobic polymer growth between the chains allowing homogeneous growth over the entire particle surface. The orderly extension of each polymer chain results in an even build-up of the polymer, which forms a layer surrounding the particles, leading to their encapsulation.

MacroRAFT (co)polymer

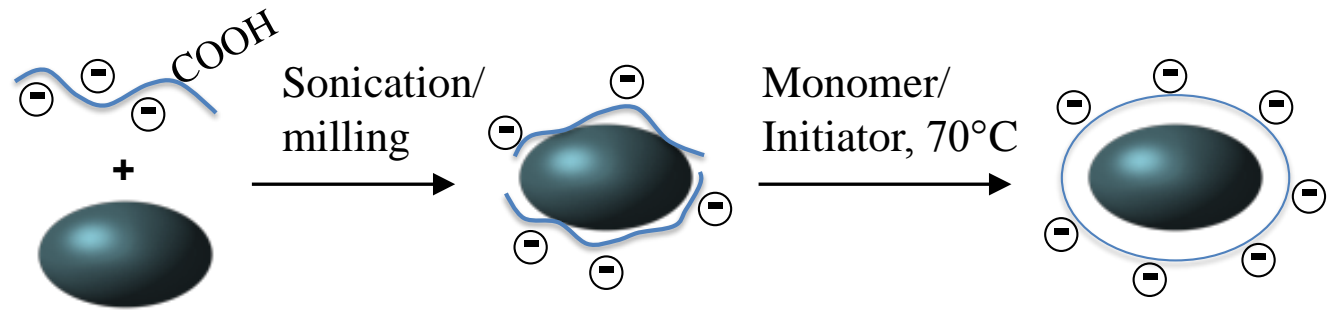

Pigment Dispersed pigment Encapsulated pigment

Fig. 10 Schematic illustration of the macroRAFT-assisted encapsulating emulsion polymerization (REEP) technique. Reproduced from [51] with permission from the American Chemical Society.

Nguyen et al. first applied this strategy to encapsulate both hydrophilic (zirconiaand alumina-coated titanium dioxide) and hydrophobic (phthalocyanine blue) pigments with poly(methyl methacrylate- $c o-n$-butyl acrylate) (P(MMA-co-BA)). The particulate materials were first mixed with short-chain random copolymers composed of AA and BA $\left(M_{\mathrm{n}}\right.$ lower than $\left.2000 \mathrm{~g} \mathrm{~mol}^{-1}\right)$, which readily adsorbed on their surface. Encapsulation polymerization was then performed at $70^{\circ} \mathrm{C}$ by slowly feeding the dispersed system with the hydrophobic monomers using 4,4'-azobis(4-cyanopentanoic acid) (ACPA) as a water-soluble initiator. The $\mathrm{pH}$ value and the copolymer composition were optimized to promote macroRAFT adsorption: the higher the hydrophobicity of the macroRAFT agent and the lower the $\mathrm{pH}$ value, the better the interaction with the particle surface. At the same time, the BA units needed to be incorporated in the polymer chains to increase the affinity of the hydrophobic monomer molecules to the particle environment, which was a key requirement for efficient encapsulation. Lastly, the random nature of the copolymer prevented the macroRAFT (co)polymers from self-assembling into micelles, which would have inevitably led to the unwanted formation of new particles via micellar 
nucleation. As shown in Fig. 11, a very uniform encapsulation was achieved for both substrates. As expected, there was only a minor fraction of free secondary particles and the entire amount of pigment introduced was found being encapsulated.

A)

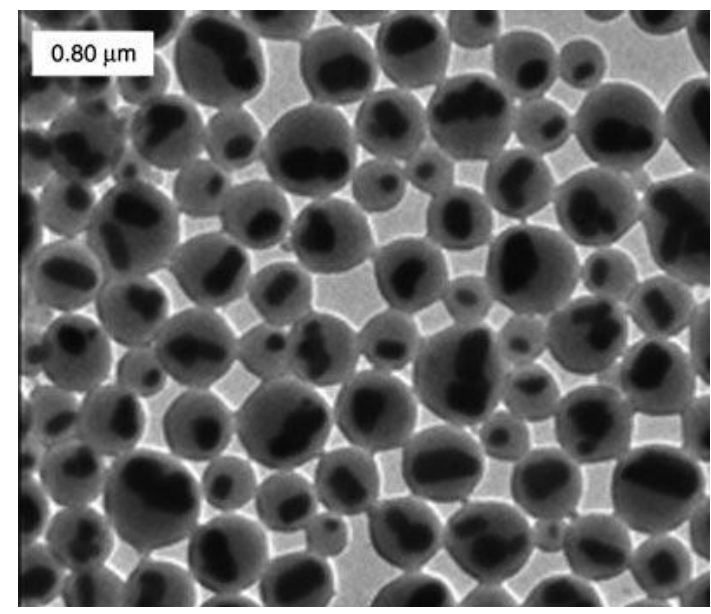

B)

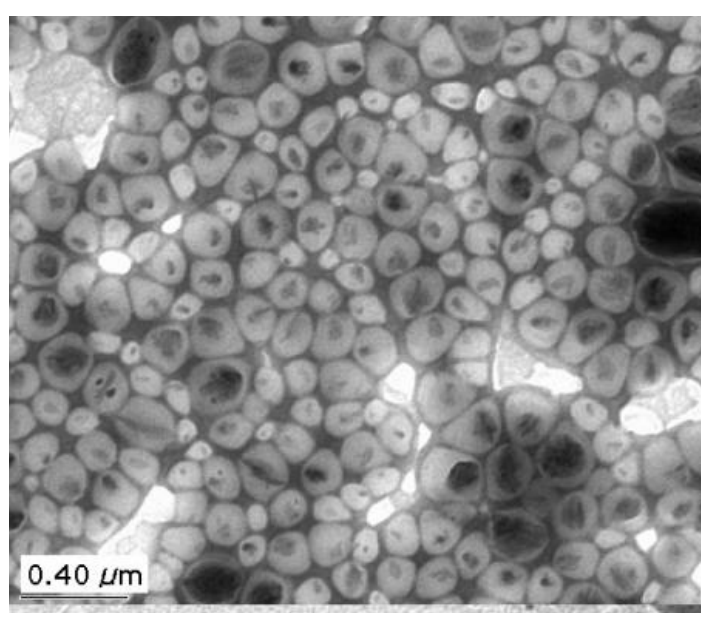

Fig. 11 TEM images of encapsulated $A) \mathrm{TiO}_{2}$ and $\mathrm{B}$ ) phthalocyanine pigment particles with $\mathrm{P}(\mathrm{MMA}-\mathrm{co}-\mathrm{BA})$ shell using $\mathrm{P}\left(\mathrm{AA}_{10}-\mathrm{Co}-\mathrm{BA}\right)$ and $\mathrm{P}\left(\mathrm{AA}_{5}-\mathrm{Co}-\mathrm{BA}_{5}\right)$ macroRAFT agents as dispersants, respectively. Reprinted from [51] with permission from the American Chemical Society.

Unlike one could have expected, careful examination of the events taking place in water revealed that despite the presence of a high initial amount of free non-adsorbing macroRAFT agent and a constant supply of monomer and free radicals, only a small fraction of the macro RAFT agent $(\sim 19 \%)$ participated in the chain extension process. In other words, the macroRAFT agent could only add hydrophobic monomers when adsorbed onto the surface of the pigment, the growth of the labile macroRAFT copolymer remaining in the aqueous phase being comparatively less favored. SEC analyses performed on the polymer chains formed during the encapsulation reaction after selective dissolution of the polymer in a mixture of THF and TFA to remove the inorganic part, showed a good control of the polymerization ( $\exists$ ranging from 1.2 to 1.7 and a good agreement between theoretical and experimental number-average molar masses), with better control being attained at low conversions. As will be shown later, the formation of very well-defined diblock copolymers is in many cases not mandatory for successful encapsulation. It is therefore clear that the key feature of this technique is not necessarily the use of CRP as a tool to precisely control the molar masses of the produced polymers, but instead the main merit of the CRP process is the fact that the living polymer chains can be reactivated during the emulsion polymerization.

In the same period, Daigle et al. reported a similar approach to encapsulate a range of inorganic compounds such as oxides $\left(\mathrm{BaTiO}_{3}, \mathrm{TiO}_{2}\right.$ [rutile and anatase], $\mathrm{Al}_{2} \mathrm{O}_{3}, \mathrm{CuO}$, $\left.\mathrm{ZrO}_{2}\right)$, metals $(\mathrm{Zn}, \mathrm{Mo})$ and nitrides $\left(\mathrm{Si}_{3} \mathrm{~N}_{4}\right)$, however employing SDS as an additional surfactant [82]. Unlike Nguyen et al., the authors here used a macroRAFT agent composed purely of AA units. In addition, the monomer (S and/or BA) was introduced at the beginning of the reaction while a solution of initiator was fed over $4 \mathrm{~h}$. Although, as stated above, such low hydrophobicity of the macroRAFT agent is unfavorable according 
to Nguyen et al., TEM analysis showed the successful formation of a thin polymer shell around the inorganic particles with an absence of aggregation. Concurrently, polymer particles devoid of inorganic cores were also formed. This new population of particles likely originates from the self-assembly of block copolymers formed in the water phase via chain extension of the free macroRAFT agent and secondary nucleation. The success of encapsulation was attributed to the large amount of inorganic particles (20 wt $\%$ ) and to the strong macroRAFT adsorption leading to a very slow exchange between the adsorbed and the free polymer chains, enabling the efficient growth of polymer chains at the particle surface. Indeed, while the adsorbed polymer is growing, it becomes more and more hydrophobic which favors shell formation whereas the free polymer becomes amphiphilic and eventually segregates into a second population of particles. According to the authors, however, macroRAFT agents displaying only weak adsorption also become more and more hydrophobic upon chain extension, and the situation is therefore analogous to the case of a strong adsorption. In contrast to the results of Nguyen et al., SEC analyses of the soluble polymer in THF indicated only a poor level of control which supports the idea that the key role of the RAFT agent is its provision of many active sites for re-initiation of chain growth, with its ability to control the polymerization being less important.

The REEP strategy was further expanded to the encapsulation of cadmium sulfide (CdS) [83] and lead sulfide (PbS) [84] QDs, still in the presence of SDS. The CdS particles were first dispersed in an aqueous solution of PAA or P(AA-Co-BA) macroRAFT agents with the help of ultrasound at $\mathrm{pH}=6$ and mixed with $\mathrm{S}$ and surfactant. The polymerization was then conducted by slowly feeding an initiator solution at $80^{\circ} \mathrm{C}$ over 4 hours and stirring for another 2 hours. In accordance with the earlier work of Nguyen et al. [51], successful encapsulation was only achieved when the random macroRAFT copolymer was employed. However, in this case, the composite particles contained a large number of aggregated QDs instead of a single-particle core. As the CdS particles had not aggregated after macroRAFT adsorption, this was attributed to the small particle size and the large number of encapsulated QDs formed in the early stages of the polymerization. These core-shell particles would be colloidally unstable and therefore agglomerate to larger particles. PbS particles were encapsulated in a similar manner. Depending on monomer, dispersant and $\mathrm{PbS}$ concentrations, particles containing a single core (for low $\mathrm{PbS}$ concentrations) or multiple cores (for higher $\mathrm{PbS}$ concentrations) were successfully obtained.

With the aim to form anisotropic polymer/inorganic composite latex particles and to control the orientation of the inorganic filler within the polymer film formed after deposition, Ali et al. used Gibbsite clay sheets as a model for platelet-like colloidal substrates [85]. Gibbsite platelets were coated with P(AA-co-BA) macroRAFT agents similar to those used by Nguyen et al., by dropwise addition of the Gibbsite suspension to the macroRAFT solution at $\mathrm{pH}=7$ until charge inversion was reached. For the polymerization experiments, the amount of macroRAFT agent was then kept at almost twice the isoelectric-point concentration to ensure that a sufficient amount of RAFT 
copolymer was present in the aqueous phase to adsorb onto the growing surface during encapsulation, providing the required stabilization. As mentioned above for the earlier work of Nguyen et al. [51], the random nature of the copolymers prevented them from self-assembling in the aqueous phase at the beginning of the polymerization, reducing the probability of secondary nucleation. However, the formation of a second population of empty particles could still not be fully avoided. The authors noticed that raising the hydrophobicity of the macroRAFT copolymer by increasing the number of BA units resulted in appreciable growth of polymer particles in the aqueous phase arguably due to the reduced solubility of the RAFT polymers, which are more likely to cause secondary nucleation. On the contrary, a decreasing BA content indeed resulted in more hydrophilic macroRAFT agents and a lower fraction of secondary particles. However, the macroRAFT agent would also exert a lower stabilizing effect on the Gibbsite particles, inevitably leading to a higher degree of nanoparticle aggregation. The best compromise was found by using a $\mathrm{P}\left(\mathrm{AA}_{10}-\mathrm{Co}-\mathrm{BA}_{5}\right)$ macroRAFT agent. It is also worth mentioning the tremendous impact of the monomer feed composition. While core-shell particles with individual platelets evenly surrounded by a thin polymer shell were successfully obtained using a 10:1 (in weight) feed of MMA and BA (Fig. 12B), the use of a MMA to BA weight ratio of 7:3 led to a loss of control over the platelet encapsulation, and additional armored morphologies were obtained as a consequence. This morphological trend was attributed to the increased hydrophobicity and higher chain mobility of the polymer shell, possibly allowing migration of the inorganic particles to the polymer/water interface to minimize interfacial energy. An even encapsulation is however crucial for the envisaged application of the formation of polymer films incorporating oriented platelets after deposition of the composite latex (Fig. 12A).

A)

(a)

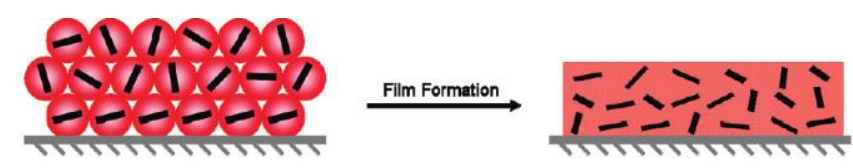

(b)

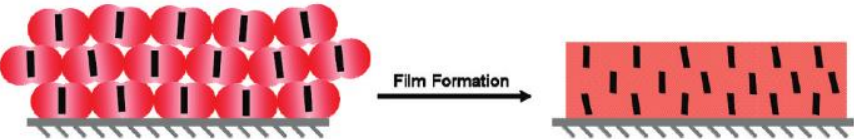

(c)

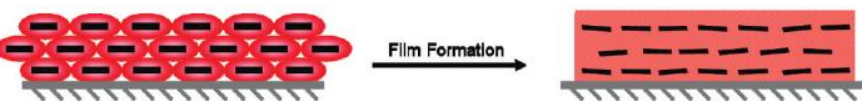

B)

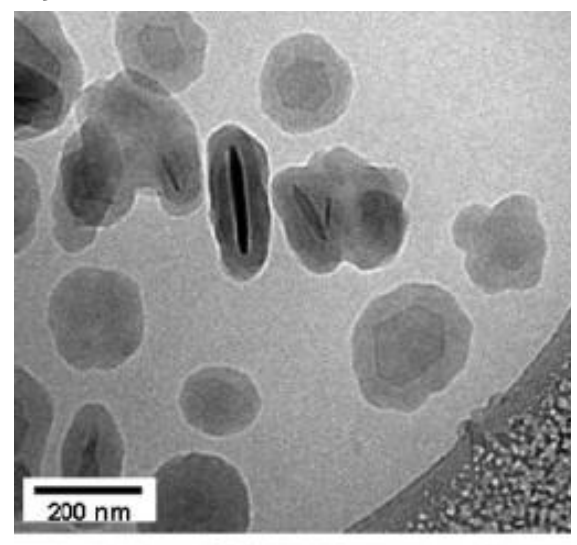

Fig. 12 A) Scheme illustrating the expected orientation of the Gibbsite platelets in the formed films for different composite latex morphologies and B) cryo-TEM image of the encapsulated Gibbsite particles with a $\mathrm{P}(\mathrm{MMA}-\mathrm{co}-\mathrm{BA})$ (weight ratio of MMA:BA $=10: 1)$ shell using a $\mathrm{P}\left(\mathrm{AA}_{5}-\mathrm{CO}-\right.$ $\mathrm{BA}_{10}$ ) macroRAFT agent. Reproduced from [85] with permission from the American Chemical Society. 
A similar approach was used by the same group to encapsulate MMT platelets using cationic RAFT copolymers composed of randomly distributed BA and quaternized units of 2-dimethylaminoethyl methacrylate (DMAEMA) and a MMA:BA (10:1 weight ratio) monomer feed [86]. Despite the successful formation of flat, cornflake-like composite particles, Brownian motion prevented them from adopting a specific orientation after deposition on a substrate.

Inspired by the seminal work of Nguyen and coworkers, our group as well reported the successful encapsulation of cerium dioxide $\left(\mathrm{CeO}_{2}\right)$ particles using the REEP technique [87]. $\mathrm{CeO}_{2}$ possesses valuable properties such as catalytic oxidation activity, UV light absorption and high scratch resistance that make it an attractive candidate for coating applications. Owing to the well-known affinity of carboxylic acid groups for $\mathrm{CeO}_{2}$, a statistical macroRAFT copolymer composed of $11 \mathrm{AA}$ and $11 \mathrm{BA}$ units (P(AA $\mathrm{A}_{11^{-}}$ co-BA $\left.\left.{ }_{11}\right), M_{\mathrm{n}}=25000 \mathrm{~g} \mathrm{~mol}^{-1}, \emptyset=1.08\right)$ was used. Adsorption was conducted by slowly adding the macroRAFT solution $(\mathrm{pH}=6.5)$ to the $\mathrm{CeO}_{2}$ suspension $(\mathrm{pH} \sim 2)$, which resulted in massive precipitation of the $\mathrm{CeO}_{2}$ particles due to screening of the surface charges originally ensuring the stability of the sol. Increasing the $\mathrm{pH}$ value to 8 in order to deprotonate the AA units allowed to re-disperse the $\mathrm{CeO}_{2}$ in the form of finite size clusters with diameters around $100 \mathrm{~nm}$. Encapsulation was finally performed by slowly feeding a mixture of MMA and BA at $70{ }^{\circ} \mathrm{C}$ using ACPA as water-soluble initiator. CryoTEM showed the successful formation of a polymer shell around the $\mathrm{CeO}_{2}$ nanoclusters resulting in complete encapsulation without any appreciable free polymer particles (Fig. 13A). Similarly to the work of Ali et al., no encapsulation was observed when BA replaced the MMA/BA mixture. This was attributed to the higher surface energy and the lower $T_{\mathrm{g}}$ of the polymer shell driving the more hydrophilic $\mathrm{CeO}_{2}$ nanoclusters towards the polymer/water interface (Fig. 13B).
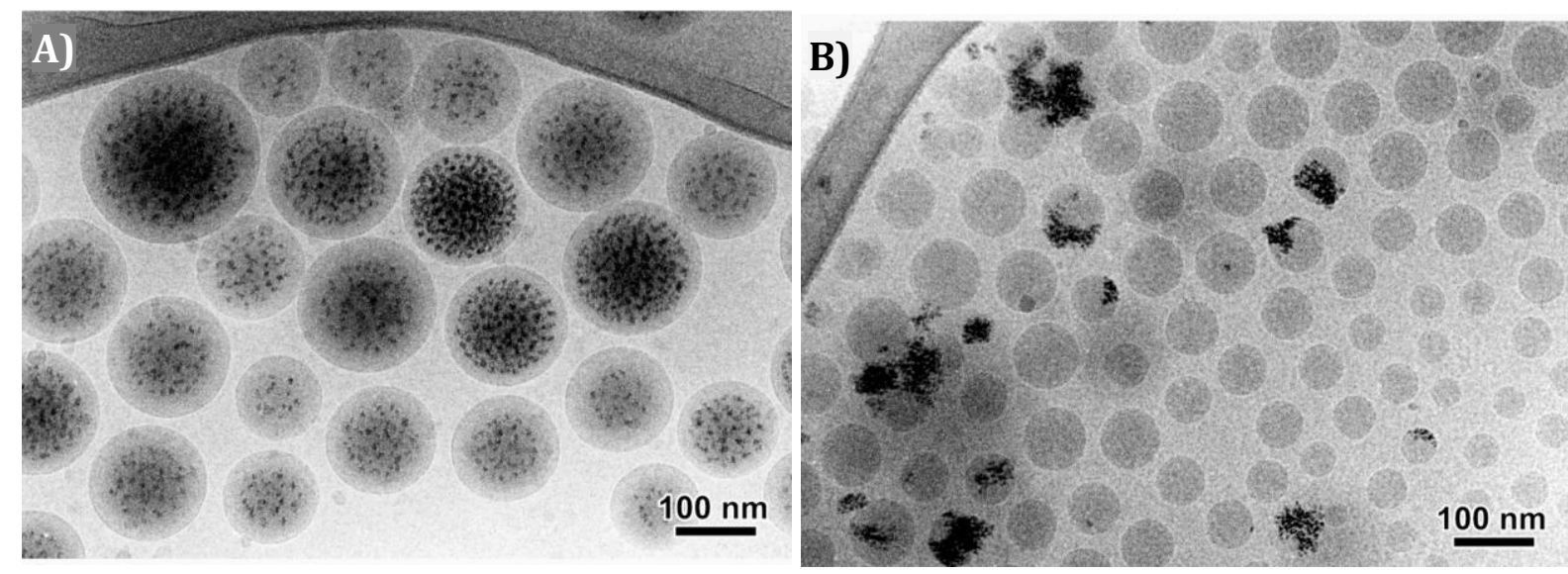

Fig. 13 Cryo-TEM images of composite latex particles obtained after emulsion polymerization of a) MMA:BA (50:50 weight ratio) and b) $\mathrm{BA}$ in the presence of $\mathrm{CeO}_{2}$ nanoclusters coated with a $\mathrm{P}\left(\mathrm{AA}_{11}-\mathrm{Co}-\mathrm{BA}_{11}\right)$ macroRAFT agent. Reproduced from [87] with permission from the Royal Society of Chemistry. 
Noteworthy are also the works of Zhong et al. [88] and Nguyen et al. [89] on the encapsulation of carbon nanotubes using the REEP technique. Zhong et al. used various types of macroRAFT agents (i.e. $\mathrm{PAA}_{40}, \mathrm{P}\left(\mathrm{AA}_{10}-\mathrm{Co}-\mathrm{BA} 5\right)$ and $\left.\mathrm{P}\left(\mathrm{AA}_{3}-\mathrm{Co}-\mathrm{S}_{3}\right)\right)$ which all proved successful to encapsulate single-wall and multi-wall carbon nanotubes upon chain extension with MMA or S, despite their poor affinity for the nanotube's surface. The carbon nanotubes were coated with a thin and regular polymer shell forming kinetically trapped morphologies as long as the monomer-feeding rate was maintained sufficiently low to avoid the formation of phase-separated domains. To increase the adsorption efficiency of the negatively charged macroRAFT agent, Nguyen et al. introduced positive groups on the nanotube surface using poly(allylamine hydrochloride) (PAH) as cationic polyelectrolyte. Subsequent adsorption of poly(4vinylbenzenesulfonic acid-co-BA) RAFT copolymer on the surface of the cationic nanotubes and chain extension with MMA/BA (10:1 weight ratio) resulted in an uniform polymer coating with complete coverage (including the tips) provided that the amount of PAH introduced in the first step was sufficiently large. Varying the amount of monomer introduced during the reaction enabled to control the shell thickness from a few nanometers to several tens of nanometers.

The potential of the REEP technique goes beyond the encapsulation of organic or inorganic particulate materials and includes the design of more elaborate systems such as the synthesis of $\mathrm{TiO}_{2}$ /polymer hybrid "nanorattles" [90]. In this work, $\mathrm{TiO}_{2}$ pigments were first encapsulated in a water-swellable polymer shell composed of MMA, BA and MAA using a poly(4-vinylbenzenesulfonic acid-co-AA-co-BA) macroRAFT agent at a low $\mathrm{pH}$ value $(\sim 4)$. The shell was subsequently coated with a hard hydrophobic layer. Hybrid nanorattles were then produced by swelling the hydrophilic layer in a basic solution at elevated temperatures followed by crosslinking of the outer polymer shell to consolidate the hollow morphology and to withstand the compressive forces that develop during the drying step (Fig. 14). Air voids were shown to be controlled by the swelling time, the temperature and the thickness of the hydrophilic polymer layer. The final $\mathrm{TiO}_{2}$-filled hollow spheres are expected to be more efficient opacifiers than both traditional and encapsulated titanium dioxide pigments and could find applications in both the paper and the architectural coatings market. 
A)

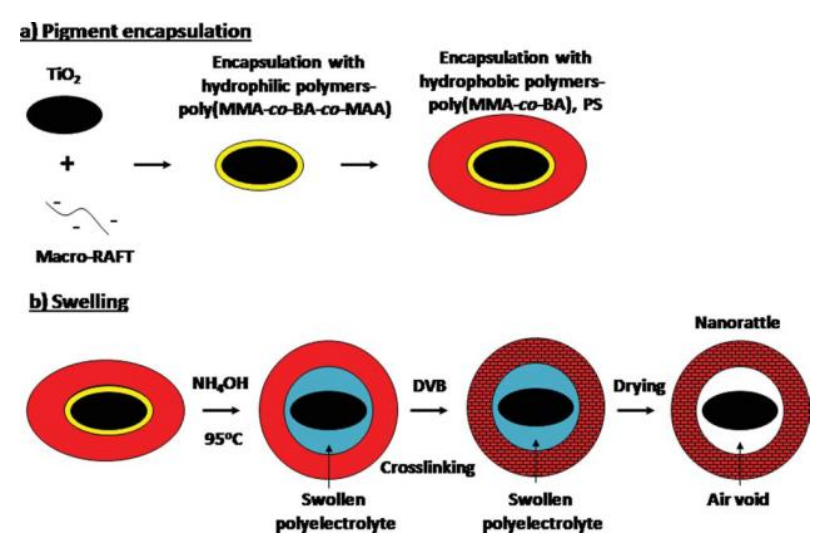

B)

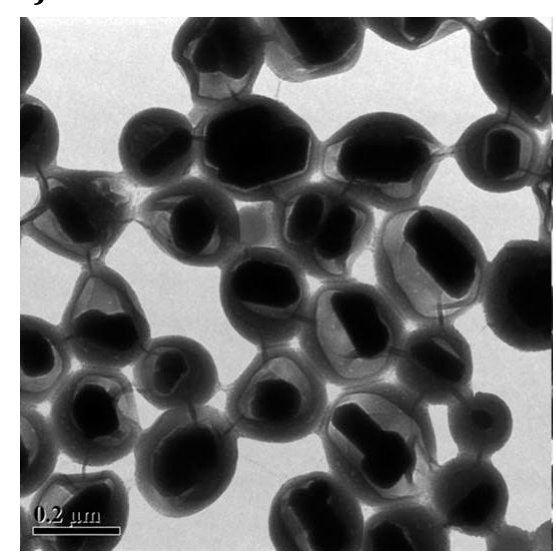

Fig. 14 a) Schematic representation of nanorattle synthesis using amphiphilic macroRAFT copolymers as stabilizers and b) TEM of nanorattles formed after swelling at $\mathrm{pH}=11$ and $95^{\circ} \mathrm{C}$ and crosslinking of the outer shell. Reproduced from [90] with permission from Wiley InterScience.

As described above, many parameters in the REEP process can influence the particle morphology, such as the $\mathrm{pH}$ value of the suspension, the feeding process (batch or semibatch), and the macroRAFT agent and hydrophobic monomer compositions. In some cases, the inorganic particles are not encapsulated, and different morphologies are formed. For instance, Garnier et al. [91] attempted to encapsulate nanoceria into poly(styrene-co-methyl acrylate) (P(S-co-MA)) latex particles using $\mathrm{P}(\mathrm{AA}-c o-\mathrm{BA}) \mathrm{RAFT}$ copolymers similar to those used by Ali et al. [85] for the encapsulation of Gibbsite platelets. However, the presence of adsorbed citric acid on the nanoceria particle surface limited macroRAFT adsorption and prevented effective encapsulation. Instead, the $\mathrm{CeO}_{2}$ particles were located on the latex surface (Fig. 15A). The use of a sulfonated macroRAFT agent with the aim of increasing latex stability and decreasing latex particle size did not result in hybrid particles at all, with the nanoceria instead remaining free in solution (Fig. 15B) [92]. This was assigned to the poor affinity of this macroRAFT agent for the $\mathrm{CeO}_{2}$ surface, again highlighting the importance of the surface properties of the macroRAFT-coated inorganic particles in determining hybrid particle morphology. The work of Warnant et al. [93] on the synthesis of $\mathrm{CeO}_{2} /$ poly(vinylidene chloride-co-methyl acrylate) hybrid latexes mediated by a phosphonated poly(vinylbenzylphosphonic acid$c o-S)$ RAFT copolymer also highlights this effect. Cryo-TEM showed composite particles decorated by several ceria particles, which were once again located at the polymer/water interface in an armored morphology. 

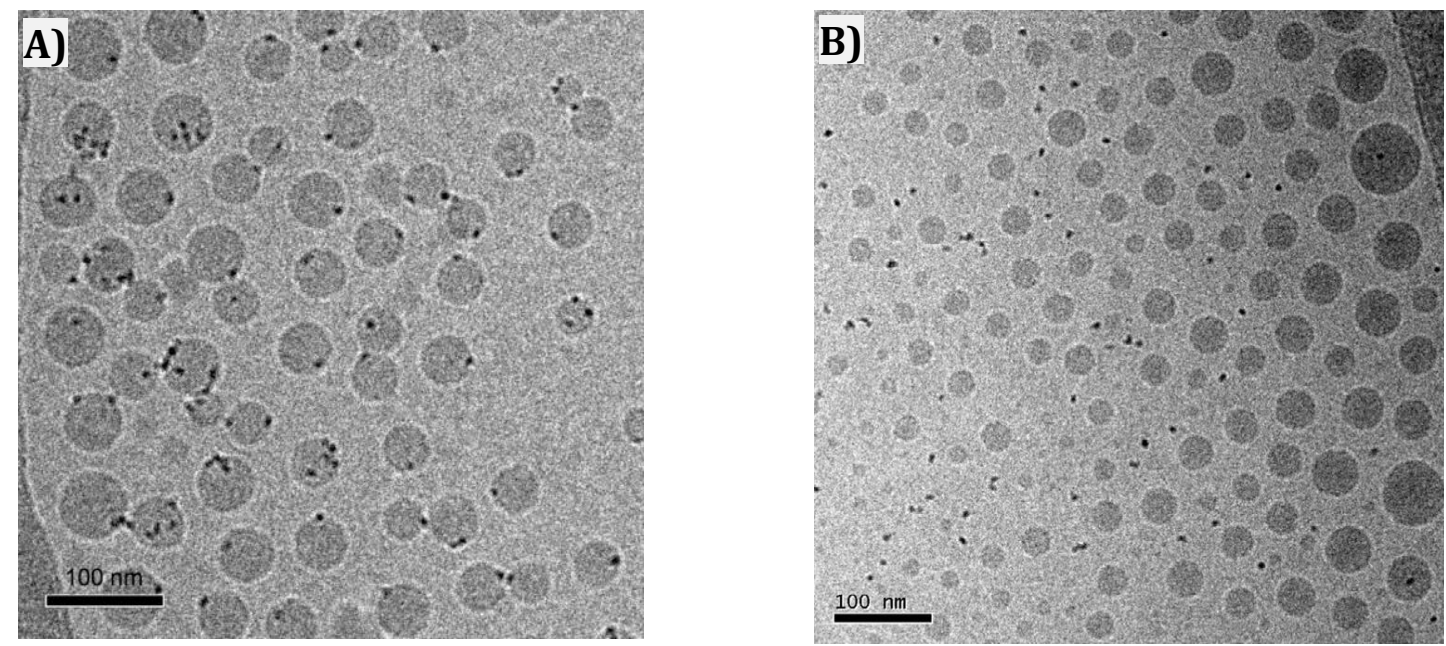

Fig. 15 Cryo-TEM images of the $\mathrm{CeO}_{2} / \mathrm{P}(\mathrm{S}-\mathrm{co}-\mathrm{MA})$ hybrid latexes obtained employing $\left.\mathrm{A}\right) \mathrm{P}\left(\mathrm{BA}_{7.5}-\right.$ co-AA $\left.{ }_{10}\right)$, and $\left.\mathrm{B}\right) \mathrm{P}\left(\mathrm{BA}_{7.2}-\mathrm{Co}^{\left.-\mathrm{AMPS}_{7.6}\right)}\right.$ macroRAFT copolymers. Reprinted with permission from [91] and [92]. Copyright 2012 Wiley-VCH and Copyright 2013 Elsevier Inc, respectively.

The transposition of CRP techniques from homogeneous systems to aqueous dispersed media, particularly ab initio emulsion polymerization, is not straightforward due to partitioning of the controlling agent between the different phases leading to transport issues from the droplets to the polymerization sites. Such issues are generally circumvented by using the polymerization-induced self-assembly (PISA) technique. However, there are still situations where the PISA process struggles to achieve a good level of control notably when using PEO-based macroRAFT agents as the hydrophilic block. Indeed, the later are still hydrophobic enough to partition to some extent to the monomer phase resulting in poor colloidal stability, low reaction rates and to high molar mass dispersities.

Aiming at designing polymer/clay hybrid latexes, a novel strategy for wellcontrolled RAFT ab initio emulsion polymerization of S with PEO-based macroRAFT agents was developed by Rodrigues-Guimarães et al. [94] in which Laponite clay platelets were used to "support" the controlling agents. Adsorption isotherms exhibited Langmuir-type profiles, indicating high affinity of the macroRAFT agent for the clay surface. Immobilization of the macroRAFT agent on the clay surface minimized its partitioning between the monomer droplets and the water phase during the subsequent polymerization, which significantly improved the latex colloidal stability and the living character of the polymerization. The best level of control was achieved for intermediate macroRAFT concentrations (Fig. 16A), which were high enough to promote colloidal stability of the latex particles while avoiding any partitioning of free non-adsorbing macroRAFT agent. The resulting composite particles exhibited an armored morphology (with the Laponite clay sheets located at the particle surface), with embedded PEO domains originating from heterocoagulation of the self-assembled block copolymers formed in the aqueous phase with the ones nucleated on the Laponite clay discs (Fig. 16B). 
A)

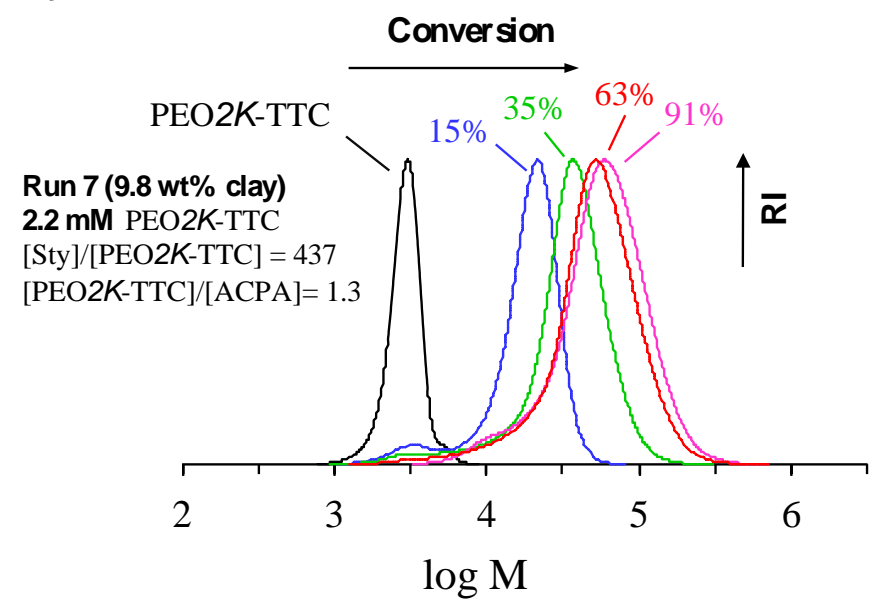

B)

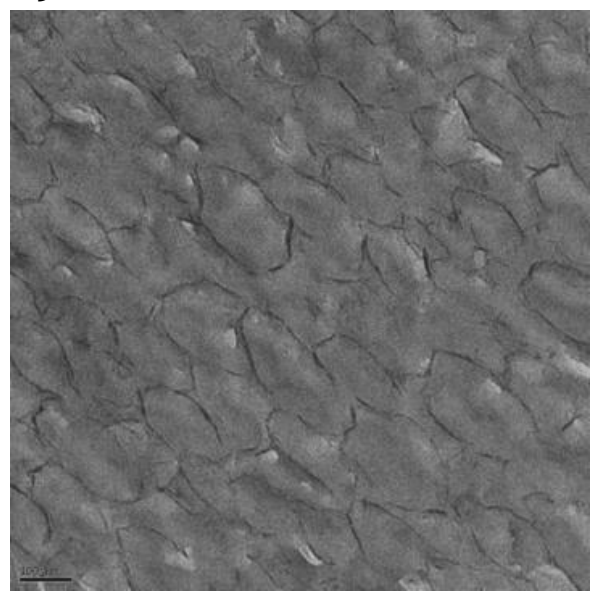

Fig. 16 A) Evolution of the size-exclusion chromatograms with monomer conversion (SEC THF, PS calibration) showing the good control of the polymerization and B) TEM image of an ultrathin cross-section of epoxy-embedded Laponite/PS composite latex particles synthesized by macroRAFT-mediated $a b$ initio emulsion polymerization of S. Reproduced from [94] with permission from the Royal Society of Chemistry.

\subsubsection{Synthesis of organic/inorganic hybrid particles by nitroxide-mediated emulsion polymerization}

While the majority of CRP-mediated syntheses of colloidal nanocomposites use RAFT polymerization to control the polymer architecture and particle morphology, NMP has also been successfully employed for the same purpose. As reviewed elsewhere, NMP has been successfully conducted in aqueous dispersed media for the so-called PISA technique (which was pioneered using RAFT polymerization) [79]. Although less versatile than RAFT polymerization in terms of monomer choice-NMP is generally incompatible with methacrylates [95] except when some specific nitroxides are employed [96] - the applicability of NMP has been expanded to methacrylate systems through a technique developed by Charleux et al. [97], in which a small amount of $\mathrm{S}$ is added to the monomer feed when preparing the macroalkoxyamine. This enhances the reversible deactivation process and forms stable alkoxyamines.

Qiao et al. [98] recently exploited this approach to synthesize water-soluble P(PEOMA-co-S)-SG1 brush-type macroalkoxyamine initiators, which were adsorbed onto colloidal silica and subsequently used to initiate the growth of BMA in aqueous emulsion and form sterically-stabilized self-assembled block copolymers. The resulting particle morphology was shown to be $\mathrm{pH}$-sensitive, which was interpreted in terms of a salting-out effect induced by the concomitant increase of ionic strength upon neutralization of the alkoxyamine initiator. In a subsequent work, these PEO-based macroalkoxyamine initiators were adsorbed onto colloidal silica and chain extended with BMA in ab initio emulsion polymerization. This resulted for the very first time in 
the formation of multipod-like silica/self-assembled block-copolymer hybrid particles with dumbbell-, raspberry-, and daisy-shaped morphologies depending on the silica particle size and the macroinitiator concentration [99].

This example and the previous ones on RAFT-mediated polymerization highlight the great potential of aqueous CRP emulsion polymerization techniques for the synthesis of organic/inorganic colloids of controllable shape, morphology, and surface functionality, thus opening the door to microstructured particles and coatings with great promise in many areas of materials science.

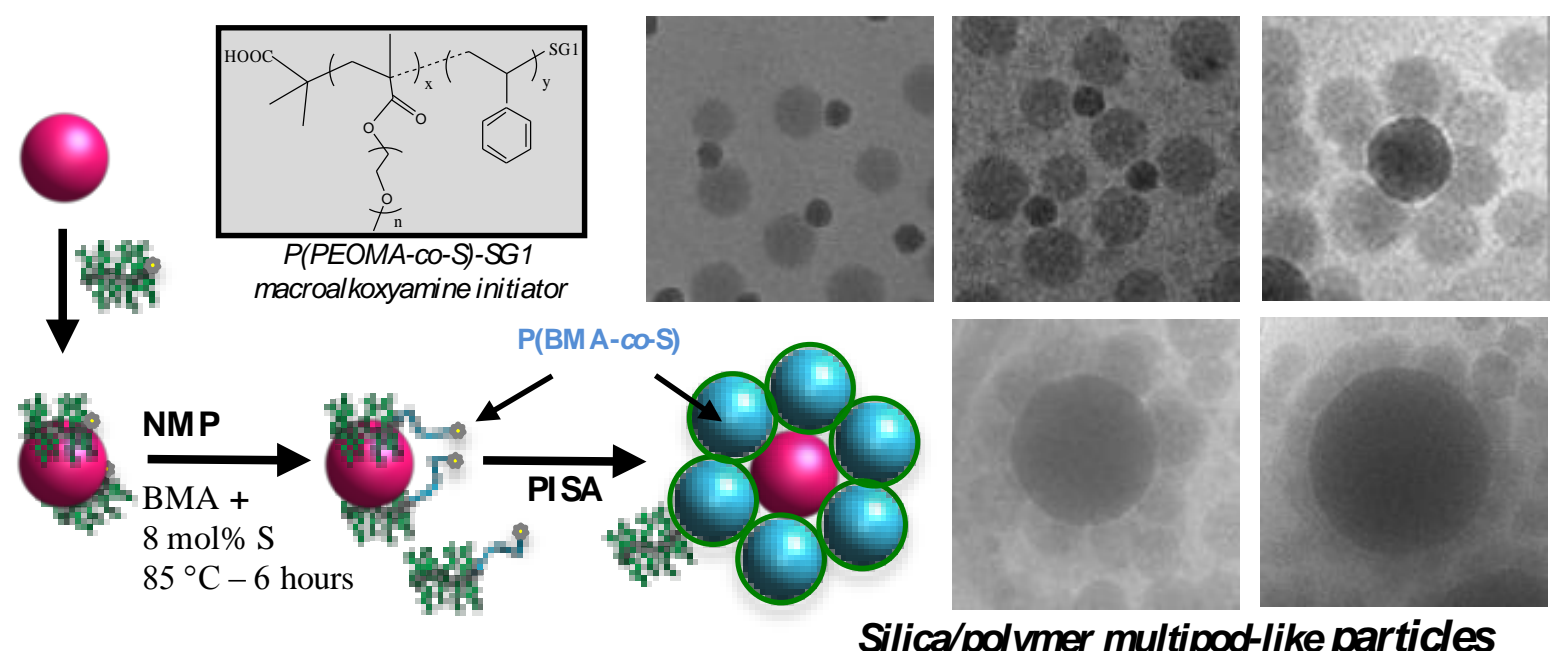

Fig. 17 Scheme illustrating the synthesis of multipod-like silica/polymer particles by NMPmediated polymerization induced self-assembly of block copolymers by means of a PEO-based brush-type macroalkoxyamine initiator previously adsorbed at the surface of colloidal silica nanoparticles. Reproduced from [99] with permission from the American Chemical Society.

\section{CONCLUSIONS}

Emulsion polymerization systems are powerful, industrially relevant tools to produce polymeric latexes. Although not transposed to industry yet, controlled radical polymerization in dispersed media should confer even greater flexibility to these systems. While in the initial application of CRP to dispersed media, control over molar masses in latexes was the primary aim, the recent developments discussed in this review focus on the ability to recommence the polymerization process from specific interfaces-either a liquid/liquid interface, or the surface of added (inorganic) particles. This is permitted by the ability of CRP to precisely tailor the affinity of pre-formed polymers for the desired interface, and to resume polymerization from the retained mediating groups. Confining the CRP to the interface combines the advantages offered by both CRP and heterogeneous polymerization systems, providing elegant pathways to new colloidal structures and morphologies. We have highlighted examples showing the innovative synthesis of nanocapsules by incorporating an inert "templating liquid" in the dispersed monomer phase, which is retained as a removable particle core after chain 
extension of the stabilizing polymers at the interface. Other original strategies in which dispersed aqueous droplets or vesicles are used as templates for nanocapsule synthesis have also been discussed. In addition, the significant advances in the integration of different types of inorganic particles into latexes facilitated by CRP polymers adsorbed to the inorganic surfaces have been highlighted. Along with the capability to chain extend, the precisely controlled composition of the CRP polymers is key to their affinity for the inorganic surfaces in both aqueous miniemulsion and emulsion systems. We can envisage continual refinement of these systems to overcome some of the challenges in attaining pure populations of the desired nanocapsule structures and polymer/inorganic nanoparticle morphologies, and expect that some of the exotic structures (e.g. "nanorattles") already produced will inspire the development of even more sophisticated motifs for new functional material applications.

ACKNOWLEDGEMENTS Drs. Bastian Ebeling and Samuel Pearson (C2P2) are gratefully acknowledged for fruitful discussions.

\section{ABBREVIATIONS}

$\mathrm{AA}$

ACPA

AIBN

A(R)GET

ATRP

BA

BAEDS

BMA

CDPA

CdS

CRP

Cryo-TEM

CTAB

$Ð$

DBTTC

DFA

DIBTC

DLS

DMAEMA

dNbPy

DODAB

DSDMA

DT acrylic acid

4,4'-azobis(4-cyanopentanoic acid)

2,2'-azobis(isobutyronitrile)

activator (re)generated by electron transfer

Atom transfer radical polymerization

$n$-butyl acrylate

bis-acryloyloxyethyl disulfide

$n$-butyl methacrylate

4-cyano-4(dodecylsulfanylthiocarbonyl)sulfanylpentanoic acid cadmium sulfide

controlled radical polymerization

cryogenic transmission electron microscopy

Cetyl trimethylammonium bromide

dispersity

dibenzyl trithiocarbonate

dodecafluoroheptyl acrylate

dodecyl isobutyric acid trithiocarbonate

dynamic light scattering

2-dimethylaminoethyl methacrylate

4,4'-dinonyl-2,2'-bipyridine

dimethyldioctadecyl ammonium bromide

bis(2-methacryloyloxyethyl)disulfide

degenerative transfer 


\begin{tabular}{|c|c|}
\hline DVB & divinylbenzene \\
\hline $\mathrm{EBiB}$ & ethyl $\alpha$-bromoisobutyrate \\
\hline EGDMA & ethylene glycol dimethacrylate \\
\hline GO & graphite oxide \\
\hline HD & hexadecane \\
\hline IMEPP & inverse miniemulsion periphery polymerization \\
\hline KPS & potassium persulfate \\
\hline MA & methyl acrylate \\
\hline macroRAFT & macromolecular RAFT agent \\
\hline MAn & maleic anhydride \\
\hline MAA & methacrylic acid \\
\hline MBA & $N, N^{\prime}$-methylenebisacrylamide \\
\hline MMA & methyl methacrylate \\
\hline MMT & montmorillonite \\
\hline$M_{\mathrm{n}}$ & number-average molar mass \\
\hline MNP & magnetic nanoparticle \\
\hline NMP & nitroxide-mediated polymerization \\
\hline NIPAM & $N$-isopropylacrylamide \\
\hline $\mathrm{OA}$ & oleic acid \\
\hline PAA & poly(acrylic acid) \\
\hline PAH & poly(allylamine hydrochloride) \\
\hline PBA & poly(n-butyl acrylate) \\
\hline PBMA & poly(n-butyl methacrylate) \\
\hline PDFA & poly(dodecafluoroheptyl acrylate) \\
\hline PDMAEMA & poly(2-dimethylaminoethyl methacrylate) \\
\hline PEO(MA) & poly(ethylene oxide) (methacrylate) \\
\hline PHPMA & $\operatorname{poly}(N$-(2-hydroxypropyl methacrylamide) $)$ \\
\hline PISA & polymerization-induced self-assembly \\
\hline PMAA & poly(methacrylic acid) \\
\hline PMMA & poly(methyl methacrylate) \\
\hline PNIPAM & poly $(N$-isopropylacrylamide $)$ \\
\hline PPPDTA & phenyl 2-propyl phenyldithioacetate \\
\hline PS & polystyrene \\
\hline QD & quantum dot \\
\hline RAFT & reversible addition-fragmentation chain transfer \\
\hline REEP & macroRAFT-mediated encapsulating emulsion polymerization \\
\hline RDRP & reversible-deactivation radical polymerization \\
\hline (R)ITP & (reverse) iodine-transfer polymerization \\
\hline SAXS & small-angle X-ray scattering \\
\hline SDBS & sodium dodecylbenzene sulfonate \\
\hline SDS & sodium dodecyl sulfate \\
\hline SG1 & $\begin{array}{l}N \text {-tert-butyl- } N \text {-[1-diethylphosphono-(2,2-dimethylpropyl)] } \\
\text { nitroxide }\end{array}$ \\
\hline
\end{tabular}




$\begin{array}{ll}\text { SR\&NI } & \text { simultaneous reverse and normal initiation } \\ \mathrm{S} & \text { styrene } \\ t \text {-BA } & \text { tert-butyl acrylate } \\ \text { TEM } & \text { transmission electron microscopy } \\ \text { TERP } & \text { organotellurium-mediated living radical polymerization } \\ \text { TFA } & \text { trifluoroacetic acid } \\ T_{\mathrm{g}} & \text { glass transition temperature } \\ \text { THF } & \text { tetrahydrofuran } \\ \text { VBTMACl } & \text { vinylbenzyl trimethylammonium chloride }\end{array}$

\section{REFERENCES}

1. Handbook of Radical Polymerization (2002). John Wiley \& Sons, Hoboken, New Jersey. 2. Gilbert RG (1995) Emulsion Polymerization: a Mechanistic Approach. Academic Press, London.

3. Lovell PA, El-Aasser MS, Editors (1997) Emulsion Polymerization and Emulsion Polymers. John Wiley and Sons.

4. Pichot C, Daniel JC, Editors (2006) Les latex synthétiques. Elaboration, Propriétés, Applications. Lavoisier, Paris.

5. Bourgeat-Lami E, Lansalot M (2010) Organic/Inorganic Composite Latexes: The Marriage of Emulsion Polymerization and Inorganic Chemistry. Adv Polym Sci 233:53123.

6. Rahman MM, Elaissari A (2010) Organic-Inorganic Hybrid Magnetic Latex. Adv Polym Sci 233:237-281.

7. Ladj R, Bitar A, Eissa MM, Fessi H, Mugnier Y, Le Dantec R, Elaissari A (2013) Polymer encapsulation of inorganic nanoparticles for biomedical applications. Int J Pharm 458:230-241.

8. Antonietti M, Landfester K (2002) Polyreactions in miniemulsions. Prog Polym Sci 27:689-757.

9. Asua JM (2002) Miniemulsion polymerization. Prog Polym Sci 27:1283-1346.

10. Schork FJ, Luo Y, Smulders W, Russum JP, Butté A, Fontenot K (2005) Miniemulsion Polymerization. Adv Polym Sci 175:129-255.

11. Cao ZH, Ziener U (2013) A versatile technique to fabricate capsules: miniemulsion. Curr Org Chem 17:30-38.

12. Asua JM (2014) Challenges for Industrialization of Miniemulsion Polymerization. Prog Polym Sci 39:1797-1826.

13. Guyot A, Landfester K, Schork FJ, Wang C (2007) Hybrid polymer latexes. Prog Polym Sci 32:1439-1461.

14. Landfester K (2009) Miniemulsion Polymerization and the Structure of Polymer and Hybrid Nanoparticles. Angew Chem Int Ed 48:2-22.

15. Weiss C, Landfester K (2010) Miniemulsion Polymerization as a Means to Encapsulate Organic and Inorganic Materials. Adv Polym Sci 233:185-236.

16. $\mathrm{Hu} \mathrm{J}$, Chen $\mathrm{M}, \mathrm{Wu} \mathrm{L}$ (2011) Organic-inorganic nanocomposites synthesized via miniemulsion polymerization. Polym Chem 2:760-772.

17. Cao Z, Ziener U (2013) Synthesis of nanostructured materials in inverse miniemulsions and their applications. Nanoscale 5:10093-10107. 
18. Qi D, Cao Z, Ziener U (2014) Recent advances in the preparation of hybrid nanoparticles in miniemulsions. Adv Colloid Interface Sci 211:47-62.

19. Zetterlund PB, Kagawa Y, Okubo M (2008) Controlled/Living Radical Polymerization in Dispersed Systems. Chem Rev 108:3747-3794.

20. Charleux B, Delaittre G, Rieger J, D'Agosto F (2012) Polymerization-induced selfassembly: from soluble macromolecules to block copolymer nano-objects in one step. Macromolecules 45:6753-6765.

21. Monteiro MJ, Cunningham MF (2012) Polymer Nanoparticles via Living Radical Polymerization in Aqueous Dispersions: Design and Applications. Macromolecules 45:4939-4957.

22. Warren NJ, Armes SP (2014) Polymerization-Induced Self-Assembly of Block Copolymer Nano-objects via RAFT Aqueous Dispersion Polymerization. J Am Chem Soc 136:10174-10185.

23. Nicolas J, Guillaneuf Y, Lefay C, Bertin D, Gigmes D, Charleux B (2013) Nitroxidemediated polymerization. Prog Polym Sci 38:63-235.

24. Matyjaszewski K (2012) Atom Transfer Radical Polymerization (ATRP): Current Status and Future Perspectives. Macromolecules 45:4015-4039.

25. Gromada J, Matyjaszewski K (2001) Simultaneous Reverse and Normal Initiation in Atom Transfer Radical Polymerization. Macromolecules 34:7664-7671.

26. Jakubowski W, Matyjaszewski K (2005) Activator Generated by Electron Transfer for Atom Transfer Radical Polymerization. Macromolecules 38:4139-4146.

27. Magenau AJD, Strandwitz NC, Gennaro A, Matyjaszewski K (2011) Electrochemically Mediated Atom Transfer Radical Polymerization. Science 332:81-84.

28. Matyjaszewski K, Gaynor S, Wang J-S (1995) Controlled Radical Polymerizations: The Use of Alkyl Iodides in Degenerative Transfer. Macromolecules 28:2093-2095.

29. Tatemoto M, Nakagawa T (1978 (Daikin Kogyo Co., Ltd.)). German Offenlegungsschrift 2729671.

30. Tonnar J, Lacroix-Desmazes P (2008) Use of Sodium Iodide as the Precursor to the Control Agent in Ab Initio Emulsion Polymerization. Angew Chem Int Ed 47:1294-1297.

31. Yamago S (2009) Precision Polymer Synthesis by Degenerative Transfer Controlled/Living Radical Polymerization Using Organotellurium, Organostibine, and Organobismuthine Chain-Transfer Agents. Chem Rev 109:5051-5068.

32. Keddie DJ, Moad G, Rizzardo E, Thang SH (2012) RAFT Agent Design and Synthesis. Macromolecules 45:5321-5342.

33. Moad G, Rizzardo E, Thang SH (2008) Radical addition-fragmentation chemistry in polymer synthesis. Polymer 49:1079-1131.

34. Lefay C, Nicolas J (2010) Controlled/Living Radical Polymerization in Aqueous Miniemulsion. In: Miniemulsion Polymerization Technology. John Wiley \& Sons, Inc., pp 173-210.

35. van Zyl AJP, Bosch RFP, McLeary JB, Sanderson RD, Klumperman B (2005) Synthesis of styrene based liquid-filled polymeric nanocapsules by the use of RAFT-mediated polymerization in miniemulsion. Polymer 46:3607-3615.

36. Luo Y, Gu H (2006) A General Strategy for Nano-Encapsulation via Interfacially Confined Living/Controlled Radical Miniemulsion Polymerization. Macromol Rapid Commun 27:21-25.

37. Luo Y, Gu H (2007) Nanoencapsulation via interfacially confined reversible addition fragmentation transfer (RAFT) miniemulsion polymerization. Polymer 48:3262-3272. 
38. Lu F, Luo Y, Li B (2007) A Facile Route to Synthesize Highly Uniform Nanocapsules: Use of Amphiphilic Poly(acrylic acid)-block-polystyrene RAFT Agents to Interfacially Confine Miniemulsion Polymerization. Macromol Rapid Commun 28:868-874.

39. Lu F, Luo Y, Li B (2010) pH Effects on the Synthesis of Nanocapsules via Interfacial Miniemulsion Polymerization Mediated by Amphiphilic RAFT Agent with the R Group of Poly(methyl acrylic acid-ran-styrene). Ind Eng Chem Res 49:2206-2212.

40. Chen H, Luo Y (2011) Facile Synthesis of Nanocapsules and Hollow Nanoparticles Consisting of Fluorinated Polymer Shells by Interfacial RAFT Miniemulsion Polymerization. Macromol Chem Phys 212:737-743.

41. Wang Y, Jiang G, Sun X, Ding M, Hu H, Chen W (2010) Preparation of shell crosslinked nanoparticles via miniemulsion RAFT polymerization. Polym Chem 1:1638-1643. 42. Li W, Matyjaszewski K, Albrecht K, Möller M (2009) Reactive Surfactants for Polymeric Nanocapsules via Interfacially Confined Miniemulsion ATRP. Macromolecules 42:8228-8233.

43. Li W, Yoon JA, Matyjaszewski K (2010) Dual-Reactive Surfactant Used for Synthesis of Functional Nanocapsules in Miniemulsion. J Am Chem Soc 132:7823-7825.

44. Lu F, Luo Y, Li B, Zhao Q, Schork FJ (2010) Synthesis of Thermo-Sensitive Nanocapsules via Inverse Miniemulsion Polymerization Using a PEO-RAFT Agent. Macromolecules 43:568-571.

45. Wang Y, Jiang G, Zhang M, Wang L, Wang R, Sun X (2011) Facile one-pot preparation of novel shell cross-linked nanocapsules: inverse miniemulsion RAFT polymerization as an alternative approach. Soft Matter 7:5348-5352.

46. Utama RH, Guo Y, Zetterlund PB, Stenzel MH (2012) Synthesis of hollow polymeric nanoparticles for protein delivery via inverse miniemulsion periphery RAFT polymerization. Chem Commun 48:11103-11105.

47. Utama RH, Stenzel MH, Zetterlund PB (2013) Inverse Miniemulsion Periphery RAFT Polymerization: A Convenient Route to Hollow Polymeric Nanoparticles with an Aqueous Core. Macromolecules 46:2118-2127.

48. Liang G, Xu J, Wang X (2009) Synthesis and Characterization of Organometallic Coordination Polymer Nanoshells of Prussian Blue Using Miniemulsion Periphery Polymerization (MEPP). J Am Chem Soc 131:5378-5379.

49. Utama RH, Drechsler M, Förster S, Zetterlund PB, Stenzel MH (2014) Synthesis of pHResponsive Nanocapsules via Inverse Miniemulsion Periphery RAFT Polymerization and Post-Polymerization Reaction. ACS Macro Lett 3:935-939.

50. Ali SI, Heuts JPA, van Herk AM (2010) Controlled Synthesis of Polymeric Nanocapsules by RAFT-Based Vesicle Templating. Langmuir 26:7848-7858.

51. Nguyen D, Zondanos HS, Farrugia JM, Serelis AK, Such CH, Hawkett BS (2008) Pigment Encapsulation by Emulsion Polymerization Using Macro-RAFT Copolymers. Langmuir 24:2140-2150.

52. Ali SI, Heuts JPA, van Herk AM (2011) Vesicle-templated pH-responsive polymeric nanocapsules. Soft Matter 7:5382-5390.

53. Bailly B, Donnenwirth A-C, Bartholome C, Beyou E, Bourgeat-Lami E (2006) SilicaPolystyrene Nanocomposite Particles Synthesized by Nitroxide-Mediated Polymerization and Their Encapsulation through Miniemulsion Polymerization. J Nanomater 2006:Article ID 76371.

54. Bombalski L, Min K, Dong H, Tang C, Matyjaszewski K (2007) Preparation of WellDefined Hybrid Materials by ATRP in Miniemulsion. Macromolecules 40:7429-7432. 
55. Ma J, Lu M, Cao C, Zhang H (2013) Synthesis and characterization of $\mathrm{PMMA} / \mathrm{SiO}_{2}$ organic-inorganic hybrid materials via RAFT-mediated miniemulsion polymerization. Polym Comp 34:626-633.

56. Ma J, Zhang H (2014) Preparation and characterization of poly(methyl methacrylate) $/ \mathrm{SiO}_{2}$ organic-inorganic hybrid materials via RAFT-mediated miniemulsion Polymerization. J Polym Res 21:1-9.

57. Mičušík M, Bonnefond A, Paulis M, Leiza JR (2012) Synthesis of waterborne acrylic/clay nanocomposites by controlled surface initiation from macroinitiator modified montmorillonite. Eur Polym J 48:896-905.

58. Khezri K, Haddadi-Asl V, Roghani-Mamaqani H, Salami-Kalajahi M (2011) Synthesis and characterization of exfoliated poly(styrene-co-methyl methacrylate) nanocomposite via miniemulsion atom transfer radical polymerization: an activators generated by electron transfer approach. Polym Comp 32:1979-1987.

59. Khezri K, Haddadi-Asl V, Roghani-Mamaqani H, Salami-Kalajahi M (2012) Synthesis of clay-dispersed poly(styrene-co-methyl methacrylate) nanocomposite via miniemulsion atom transfer radical polymerization: A reverse approach. J Appl Polym Sci 124:2278-2286.

60. Khezri K, Haddadi-Asl V, Roghani-Mamaqani H, Salami-Kalajahi M (2012) Nanoclayencapsulated polystyrene microspheres by reverse atom transfer radical polymerization. Polym Comp 33:990-998.

61. Khezri K, Haddadi-Asl V, Roghani-Mamaqani H, Salami-Kalajahi M (2012) Encapsulation of organomodified montmorillonite with PMMA via in situ SR\&NI ATRP in miniemulsion. J Polym Res 19:1-10.

62. Hatami L, Haddadi-Asl V, Roghani-Mamaqani H, Ahmadian-Alam L, Salami-Kalajahi M (2011) Synthesis and characterization of poly(styrene-co-butyl acrylate)/clay nanocomposite latexes in miniemulsion by AGET ATRP. Polym Comp 32:967-975.

63. Khezri K, Haddadi-Asl V, Roghani-Mamaqani H, Salami-Kalajahi M (2012) Synthesis of well-defined clay encapsulated poly(styrene-co-butyl acrylate) nanocomposite latexes via reverse atom transfer radical polymerization in miniemulsion. J Polym Eng 32:111119.

64. Hatami L, Haddadi-Asl V, Ahmadian-Alam L, Roghani-Mamaqani H, Salami-Kalajahi M (2013) Effect of Nanoclay on Styrene and Butyl Acrylate AGET ATRP in Miniemulsion: Study of Nucleation Type, Kinetics, and Polymerization Control. Int J Chem Kinet 45:221235.

65. Samakande A, Sanderson RD, Hartmann PC (2008) Encapsulated clay particles in polystyrene by RAFT mediated miniemulsion polymerization. J Polym Sci Part A: Polym Chem 46:7114-7126.

66. Samakande A, Sanderson RD, Hartmann PC (2009) Rheological properties of RAFTmediated poly(styrene-co-butyl acrylate)-clay nanocomposites [P(S-co-BA)-PCNs]: Emphasis on the effect of structural parameters on thermo-mechanical and melt flow behaviors. Polymer 50:42-49.

67. Samakande A, Juodaityte JJ, Sanderson RD, Hartmann PC (2008) Novel Cationic RAFT-Mediated Polystyrene/Clay Nanocomposites: Synthesis, Characterization, and Thermal Stability. Macromol Mater Eng 293:428-437.

68. Esteves ACC, Bombalski L, Trindade T, Matyjaszewski K, Barros-Timmons A (2007) Polymer Grafting from CdS Quantum Dots via AGET ATRP in Miniemulsion. Small 3:1230-1236.

69. Esteves ACC, Hodge P, Trindade T, Barros-Timmons AMMV (2009) Preparation of nanocomposites by reversible addition-fragmentation chain transfer polymerization 
from the surface of quantum dots in miniemulsion. J Polym Sci, Part A: Polym Chem 47:5367-5377.

70. Chakraborty S, Jähnichen K, Komber H, Basfar AA, Voit B (2014) Synthesis of Magnetic Polystyrene Nanoparticles Using Amphiphilic Ionic Liquid Stabilized RAFT Mediated Miniemulsion Polymerization. Macromolecules 47:4186-4198.

71. Gu Y, Zhao J, Liu Q, Zhou N, Zhang Z, Zhu X (2014) Zero-valent iron (Fe(0)) mediated RAFT miniemulsion polymerization: a facile approach for the fabrication of $\mathrm{Fe}(0)$ encapsulated polymeric nanoparticles. Polym Chem 5:4215-4218.

72. Zhang Z, Wang W, Cheng Z, Zhu J, Zhou N, Yang Y, Tu Y, Zhu X (2010) Zero-valent Iron/RAFT Agent-Mediated Polymerization of Methyl Methacrylate at Ambient Temperature. Macromolecules 43:7979-7984.

73. Etmimi HM, Tonge MP, Sanderson RD (2011) Synthesis and characterization of polystyrene-graphite nanocomposites via surface RAFT-mediated miniemulsion polymerization. J Polym Sci, Part A: Polym Chem 49:1621-1632.

74. Kang Y, Taton TA (2005) Core/Shell gold nanoparticles by self-assembly and crosslinking of micellar, block-copolymer shells. Angew Chem Int Ed 44:409-412.

75. Hickey RJ, Haynes AS, Kikkawa JM, Park SJ (2011) Controlling the self-assembly structure of magnetic nanoparticles and amphiphilic block-copolymers: from micelles to vesicles. J Am Chem Soc 133:1517-1525.

76. Mai YE, A. (2012) Selective Localization of Preformed Nanoparticles in Morphologically Controllable Block Copolymer Aggregates in Solution. Accounts Chem Res 45:1657-1666.

77. Wang J, Li W, Zhu J (2014) Encapsulation of inorganic nanoparticles into block copolymer micellar aggregates: Strategies and precise localization of nanoparticles. Polymer 55:1079-1096.

78. Liang R, Xu J, Li W, Liao Y, Wang K, You J, Zhu J, Jiang W (2015) Precise Localization of Inorganic Nanoparticles in Block Copolymer Micellar Aggregates: From Center to Interface. Macromolecules 48:256-263.

79. Zetterlund PBK, Y.; Okubo, M. (2008) Controlled/Living Radical Polymerization in Dispersed Systems. Chem Rev 108:3747-3794.

80. Charleux B, D'Agosto F, Delaittre G (2010) Preparation of hybrid latex particles and core-shell particles through the use of controlled radical polymerization techniques in aqueous media. Adv Polym Sci 233:125-183.

81. Cenacchi-Pereira A, Grant E, D’Agosto F, Lansalot M, Bourgeat-Lami E (2015) Encapsulation with the Use of Controlled Radical Polymerization. Encyclopedia of Polymeric Nanomaterials. Springer-Verlag Berlin Heidelberg. doi:10.1007/978-3-64236199-9_347-1

82. Daigle J-C, Claverie JP (2008) A Simple Method for Forming Hybrid Core-Shell Nanoparticles Suspended in Water. J Nanomater 2008:Article ID 609184.

83. Das P, Zhong W, Claverie J (2011) Copolymer nanosphere encapsulated CdS quantum dots prepared by RAFT copolymerization: synthesis, characterization and mechanism of formation. Colloid Polym Sci 289:1519-1533.

84. Das P, Claverie JP (2012) Synthesis of single-core and multiple-core core-shell nanoparticles by RAFT emulsion polymerization: Lead sulfide-copolymer nanocomposites. J Polym Sci, Part A: Polym Chem 50:2802-2808.

85. Ali SI, Heuts JPA, Hawkett BS, van Herk AM (2009) Polymer Encapsulated Gibbsite Nanoparticles: Efficient Preparation of Anisotropic Composite Latex Particles by RAFTBased Starved Feed Emulsion Polymerization. Langmuir 25:10523-10533. 
86. Mballa Mballa MA, Ali SI, Heuts JPA, van Herk AM (2012) Control of the anisotropic morphology of latex nanocomposites containing single montmorillonite clay particles prepared by conventional and reversible addition-fragmentation chain transfer based emulsion polymerization. Polym Int 61:861-865.

87. Zgheib N, Putaux J-L, Thill A, Bourgeat-Lami E, D'Agosto F, Lansalot M (2013) Cerium oxide encapsulation by emulsion polymerization using hydrophilic macroRAFT agents. Polym Chem 4:607-614.

88. Zhong W, Zeuna JN, Claverie JP (2012) A versatile encapsulation method of noncovalently modified carbon nanotubes by RAFT polymerization. J Polym Sci, Part A: Polym Chem 50:4403-4407.

89. Nguyen D, Such CH, Hawkett BS (2013) Polymer coating of carboxylic acid functionalized multiwalled carbon nanotubes via reversible addition-fragmentation chain transfer mediated emulsion polymerization. J Polym Sci, Part A: Polym Chem 51:250-257.

90. Nguyen D, Such C, Hawkett B (2012) Polymer-TiO ${ }_{2}$ composite nanorattles via RAFTmediated emulsion polymerization. J Polym Sci; Part A: Polym Chem 50:346-352.

91. Garnier J, Warnant J, Lacroix-Desmazes P, Dufils P-E, Vinas J, Vanderveken Y, van Herk AM (2012) An Emulsifier-Free RAFT-Mediated Process for the Efficient Synthesis of Cerium Oxide/Polymer Hybrid Latexes. Macromol Rapid Commun 33:1388-1392.

92. Garnier J, Warnant J, Lacroix-Desmazes P, Dufils P-E, Vinas J, van Herk A (2013) Sulfonated macro-RAFT agents for the surfactant-free synthesis of cerium oxide-based hybrid latexes. J Colloid Interface Sci 407:273-281.

93. Warnant J, Garnier J, van Herk A, Dufils P-E, Vinas J, Lacroix-Desmazes P (2013) A $\mathrm{CeO}_{2}$ /PVDC hybrid latex mediated by a phosphonated macro-RAFT agent. Polym Chem 4:5656-5663.

94. Rodrigues Guimarães T, de Camargo Chaparro T, D'Agosto F, Lansalot M, Martins Dos Santos A, Bourgeat-Lami E (2014) Synthesis of multi-hollow clay-armored latexes by surfactant-free emulsion polymerization of styrene mediated by poly(ethylene oxide)based macroRAFT/Laponite complexes. Polym Chem 5:6611-6622.

95. McHale R, Aldabbagh F, Zetterlund PB (2007) The role of excess nitroxide in the SG1 ( $N$-tert-butyl- $N$-[1-diethylphosphono-(2,2-dimethylpropyl)] nitroxide)-mediated polymerization of methyl methacrylate. J Polym Sci, Part A: Polym Chem 45:2194-2203.

96. Detrembleur C, Jerome C, Winter JD, Gerbaux P, Clement J-L, Guillaneuf Y, Gigmes D (2014) Nitroxide mediated polymerization of methacrylates at moderate temperature. Polym Chem 5:335-340.

97. Charleux B, Nicolas J, Guerret O (2005) Theoretical Expression of the Average Activation-Deactivation Equilibrium Constant in Controlled/Living Free-Radical Copolymerization Operating via Reversible Termination. Application to a Strongly Improved Control in Nitroxide-Mediated Polymerization of Methyl Methacrylate. Macromolecules 38:5485-5492.

98. Qiao XG, Lansalot M, Bourgeat-Lami E, Charleux B (2013) Nitroxide-Mediated Polymerization-Induced Self-Assembly of Poly(poly(ethylene oxide) methyl ether methacrylate-co-styrene)- $b$-poly( $n$-butyl methacrylate-co-styrene) Amphiphilic Block Copolymers. Macromolecules 46:4285-4295.

99. Qiao XG, Dugas PY, Charleux B, Lansalot M, Bourgeat-Lami E (2015) Synthesis of Multipod-like Silica/Polymer Latex Particles via Nitroxide-Mediated PolymerizationInduced Self-Assembly of Amphiphilic Block Copolymers. Macromolecules 48:545-556. 